\title{
DIAGNÓSTICO DE LA RED ACTUAL DE CARRIL BICI DE ALCALÁ DE HENARES Y PROPUESTA DE AMPLIACIÓN PARA MEJORAR SU EFICIENCIA
}

\author{
JUAN JOSÉ NÚÑEZ LUCENA \\ Geospatial GIS Processor en NM Group \\ 8 Manse Lane, Knaresborough (North Yorkshire, United Kingdom), HG5 8LF \\ juanjon190@gmail.com
}

\begin{abstract}
RESUMEN
Como consecuencia de la complicada planificación que ha experimentado el carril bici en la ciudad de Alcalá de Henares (Madrid), el trazado resultante tras las obras de 2009, ha dejado patente estar muy lejos de las necesidades de los usuarios así como de las normas estatales recogidas en la Ley de Seguridad Vial. Este trabajo trata de buscar una solución al problema estructural que presenta el entramado del carril bici, dotándolo de coherencia y utilidad. De este modo se persigue equipar a la ciudad con una infraestructura que sirva como alternativa de transporte sostenible frente a la demanda cada vez mayor de las ciudades para reducir la emisión de gases contaminantes y el consumo excesivo de energías no renovables.
\end{abstract}

Palabras clave: carril bici, planificación urbana, coherencia, eficiencia, transporte alternativo.

\section{AN ANALYSIS OF THE CURRENT BIKE LANE NETWORK IN ALCALÁ DE HENARES AND A PROPOSED EXPANSION TO IMPROVE ITS EFFICIENCY}

\begin{abstract}
As a result of the complicated planning that the bike lane has in the city of Alcalá de Henares (Madrid), it is clear that the resulting path after the works of 2009 neither meets the needs of users nor the state standards contained in the Road Safety Act. This paper tries to find a solution to the structural problem of bike lanes, providing them with consistency and usefulness. Thereby, it seeks to equip the city with an infrastructure to serve as a sustainable transport alternative in the face of the growing demands in cities to reduce greenhouse gas emissions and excessive consumption of nonrenewable energy.
\end{abstract}

Keywords: bike lane, urban planning, coherence, efficiency, alternative transportation. 
Núñez Lucena, J.J. (2018): "Propuesta de catálogo normalizado de objetos aeronáuticos para el Ecuador", GeoFocus (Artículos), no 22, p. 43-70. ISSN: 1578-5157 http://dx.doi.org/10.21138/GF.605

\section{Introducción}

\subsection{Planteamiento del problema}

La incipiente demanda en España de medios de transporte alternativos, resulta evidente en los últimos tiempos. Desde hace poco menos de una década, se ha podido contemplar cómo en muchas ciudades, se ha apostado por la bicicleta como medio de transporte alternativo. Se han implantado cientos de kilómetros de carril bici en ciudades como: Sevilla, Valencia, Madrid y por supuesto también en Alcalá de Henares. Esto implica tomar como referentes ciudades europeas con una tradición y experiencia bastante consolidada (Ámsterdam, Copenhague, Berlín, etc.). A pesar de que la bicicleta, como medio de transporte, comienza a ser utilizada a finales del S. XIX, ésta no ocupará un papel relevante como medio alternativo hasta la década de los 80 del S. XX. Para entender mejor el porqué de lo planteado, se debe remitir primero al contexto de la situación.

La invención del automóvil supuso una auténtica revolución de los medios de transporte terrestres. No sería hasta después de 1908, momento en el que aparece el modelo de producción en cadena implantado por Henry Ford, cuando se masifica la producción de automóviles, comenzando a protagonizar un papel principal en las calles de las ciudades y en los caminos y vías que las conectan. Desde entonces, es incuestionable el papel protagonista del automóvil como medio de transporte en el ámbito terrestre. No obstante, entre 1978 y 1979 tiene lugar un hito de gran relevancia histórica, el cual haría replantear seriamente el modelo de producción y, a la larga, reflexionar sobre las prioridades energéticas. El desarrollo de determinados conflictos bélicos en Oriente Medio entre países de la OPEP (Organización de Países Exportadores de Petróleo), provocarían una seria crisis energética. Ésta fue debida a un incremento repentino del precio de los barriles de crudo, lo que afectó seriamente a la economía de los países industrializados. (CEPAL, 2001)

Al calor de la segunda crisis energética, después de la II Guerra Mundial (1939-1945), surge un movimiento (la llamada contracultura) que pone en cuestión el modelo productivo de la sociedad industrial moderna tan agresivo con el medio ambiente. Plantea la necesidad de gestionar de forma responsable los recursos naturales y avanzar hacia un desarrollo sostenible. Este movimiento materializa sus bases, en la Declaración de Río sobre el Medio Ambiente y el Desarrollo en junio de 1992, bajo la idea de satisfacer las necesidades de la sociedad actual sin arriesgar las de las generaciones venideras así como la necesidad inminente de construir ciudades habitables y sostenibles. (Avedaño, 2011)

De todos los gases efecto invernadero que se contemplaron en el protocolo de Kyoto (1997) el más relacionado con la ciudad y el transporte urbano es el $\mathrm{CO}^{2}$. En la ciudad de Madrid, los transportes aportan el $47 \%$ de $\mathrm{CO}^{2}$, a la atmósfera, de los cuales el $55 \%$ corresponde a vehículos privados. La creciente demanda de energías no renovables y la correspondiente generación de residuos contaminantes provoca un aumento preocupante de la huella ecológica y una sobrecarga de la capacidad del ecosistema urbano, lo cual hace necesario tomar ciertas medidas preventivas y correctoras en diversos ámbitos del urbanismo, entre ellos la movilidad y el transporte, en concreto la potenciación de los desplazamientos a pie y en bicicleta. (Higueras, 2009, 24-25; 82-83)

La reciente mentalidad construida sobre fuertes principios ambientalistas inclinó la mirada hacia la bicicleta como medio de transporte alternativo no motorizado para contribuir a la configuración de ciudades sostenibles. Es imprescindible que el urbanismo tenga que "orientarse hacia tendencias más ambientalistas no sólo por cuestiones de protección ambiental, 
Núñez Lucena, J.J. (2018): "Propuesta de catálogo normalizado de objetos aeronáuticos para el Ecuador", GeoFocus (Artículos), no 22, p. 43-70. ISSN: 1578-5157 http://dx.doi.org/10.21138/GF.605

sino de coherencia con un entorno adecuado necesario para el desarrollo del ser humano" (Domínguez y Lezama, 2006, 161)

Entre las ventajas destacables de apostar por la bicicleta como medio alternativo de transporte en un contexto de desarrollo sostenible encontramos las siguientes:

- Contribuye a retornar la degradación ambiental urbana.

- Reduce las emisiones de gases efecto invernadero y contribuye a la lucha en contra del cambio climático.

- Disminuye la contaminación acústica.

- Evita la segregación espacial y favorece la configuración de un urbanismo menos dependiente del automóvil, más compacto y menos impersonal. Esto se debe a que el transporte motorizado requiere más espacio para sus infraestructuras viales por lo que la ciudad necesita expandirse más, necesitando "devorar" cada vez más territorio y creando espacios monofuncionales (polígonos industriales, ciudades dormitorio, áreas de ocio, etc.). A su vez este hecho hace a las personas dependientes del automóvil. (Estevan y Sanz., 1996, 107-121)

- El uso generalizado de la bicicleta favorece la descongestión de tráfico en las ciudades y disminuye la concentración de polución, obteniendo de este modo un doble beneficio.

- Contribuye a mejorar la salud de los usuarios como consecuencia de la actividad física que implica. Los efectos positivos son varios: reduce el riesgo de infarto, quema calorías y ayuda a reducir la obesidad, tonifica los músculos, reduce el estrés y ayuda a dormir mejor, etc.

Llegados a este punto cabe preguntarse si la construcción de carriles bici favorece e incentiva su uso como medio de transporte. En 1986 Jan Gehl, uno de los arquitectos más influyentes en el urbanismo de Copenhague de las últimas décadas, comenzó a llevar cabo un estudio sobre las actividades urbanas. Concluyendo en el mismo que "las actividades exteriores están muy influidas por la configuración física" de la ciudad. Halló que entre 1968 y 1986 el número de calles y plazas peatonales del centro de Copenhague se había triplicado en consonancia con el número de personas de pie y sentadas en dichos espacios. Este estudio fue completado con observaciones en otras ciudades de Australia y Estados Unidos, observando también el comportamiento inverso donde a raíz de la construcción de grandes avenidas había aumentado el tráfico rodado. Según sus conclusiones, la calidad de las actividades sociales exteriores de la ciudad está condicionada por las posibilidades que el entorno urbano pueda ofrecer, guardando una fuerte correlación. No obstante, para que ello sea posible es necesaria una planificación adecuada de los proyectos urbanísticos que propicie el desarrollo de las actividades que se desean potenciar. Con esta visión se pretende respaldar la idea de que el carril bici de Alcalá de Henares no ha sido un proyecto fracasado porque los ciudadanos/as rechacen la idea de emplear la bicicleta como medio de transporte alternativo sino que más bien ha sido un proyecto que carece del éxito esperado debido a una mala planificación de la infraestructura en su correcta integración en el contexto urbano. (Gehl, 2003, 39-47)

Admitiendo entonces que un adecuado diseño de la red de vías ciclables, favorece una progresiva migración hacia ese medio de transporte, hemos de convenir también en que su implantación supone, en la mayoría de los casos, la sobreimposición de una nueva infraestructura sobre el entramado viario ya existente, con las previsibles dificultades de adaptación que ellos supone. En el caso de Alcalá de Henares, a lo anterior se une el problema de un entramado urbano complejo: al casco medieval y barroco, se le adosan de forma poco coherente grandes piezas industriales y residenciales en los años 60 y 70 del pasado siglo con 
Núñez Lucena, J.J. (2018): "Propuesta de catálogo normalizado de objetos aeronáuticos para el Ecuador", GeoFocus (Artículos), no 22, p. 43-70. ISSN: 1578-5157 http://dx.doi.org/10.21138/GF.605

una pobre calidad constructiva y urbanísticas; a partir de los 90, el nodo alcalaíno, dentro del área metropolitana, se dota de nuevas áreas residenciales y terciarias al gusto de las necesidades de la etapa postindustrial. Casi tres ciudades, adyacentes entre sí, pero cuya articulación no ha sido adecuadamente resuelta. No es difícil entender, entonces, que la red de carril bici (materializada en su mayor parte durante los pocos meses en que estuvo vigente el Plan E) se vea influenciada. La que debería ser una conexión continua, resultó en una serie de tramos aislados e inconexos con la presencia de algunos recorridos peligrosos. Se debe entender por red como: "una conexión continua entre diferentes carriles donde no existe un aislamiento entre ellos y todas las zonas de la ciudad quedan articuladas con una disposición estructural". (Gutiérrez, 2014, 51; Ministerio de cultura, 12-13)

Según un documento publicado por la Diputación Foral de Bizkaia, las bicicletas cubren de forma eficiente distancias de entre 7 y $15 \mathrm{~km}$, mientras que la mitad de los itinerarios recorridos por los coches son de menos de $5 \mathrm{~km}$, "una distancia que se puede recorrer en bici en 10 minutos si es terreno llano". Un trabajo similar realizado por la Comisión Europea demostró que por razones de tiempo la bicicleta es el medio de transporte más eficiente en recorridos de media distancia $(0.5$ y $5 \mathrm{~km})$. Además un estudio reciente llevado a cabo por la Universidad Complutense de Madrid reveló que, a diferencia de los usuarios de otros vehículos motorizados, los usuarios de la bicicleta tienen en cuenta un número más amplio de factores, en términos generales, a la hora de tomar su decisión. No obstante el tiempo y el coste son una prioridad que se antepone al resto de factores a tener en consideración. Es por ello que en el presente trabajo, el peso de la metodología recae en la reducción del tiempo de los recorridos en bici respecto a la red actual y al transporte público urbano como clave principal para justificar la viabilidad de ampliar el carril bici e incrementar el uso de la bicicleta. (Diputación Foral Bizkaia, 1; European Commission, 11; Fernández, 3-4)

Una vez revisada esta trayectoria se puede atender a la identificación de los principales problemas en los que se centra el presente trabajo. Por un lado se presenta la necesidad de apostar por medios de transporte que sean beneficiosos para el medio ambiente. Por otro lado, se hace constar la presencia de una red de carril bici con una estructura inconexa, carente de sentido y utilidad. Además se resalta la falta de voluntad por parte de los agentes políticos, para llevar a cabo una buena planificación integrada en las políticas de Ordenación del Territorio, para evitar conflictos entre vehículos motorizados y no motorizados, que igualmente trate de motivar a la sociedad a priorizar el uso de los segundos.

\subsection{Objetivos}

El objetivo principal que persigue el presente trabajo es la detección de las diferentes irregularidades estructurales que presenta la red de carril bici de Alcalá de Henares. Del mismo modo se persigue la identificación y empleo de las herramientas apropiadas para dar solución a la estructura inconexa e incoherente de la red así como poner a disposición de los ciudadanos/as un servicio que, a pesar de ser demandado y de existir la infraestructura como tal, no es utilizado.

Para mayor precisión se requiere distinguir entre objetivos generales y específicos:

\section{a) Objetivos generales}

- Identificar las diferentes herramientas útiles que permitan brindar al espacio de una diligente conexión y adecuar la red de ciclovías en el entramado viario a fin de conformar un entorno coherente. 
Núñez Lucena, J.J. (2018): "Propuesta de catálogo normalizado de objetos aeronáuticos para el Ecuador", GeoFocus (Artículos), no 22, p. 43-70. ISSN: 1578-5157 http://dx.doi.org/10.21138/GF.605

- Presentar o exponer un método o flujo de trabajo que permita evaluar y analizar la calidad de una red en términos de tiempo.

- Definir la terminología básica referente a la tipología de vías ciclables.

\section{b) Objetivos específicos}

- Cartografiar la red carril bici de Alcalá de Henares y realizar un inventariado atendiendo a diferentes criterios.

- Evaluar la red actual en términos de seguridad, coherencia y conectividad.

- Proponer una extensión de la red actual, a fin de conformar una nueva dispuesta de conexión y coherencia que sea más eficiente y permita revitalizar su uso.

- Realizar y exponer los resultados de un análisis de redes a fin de evaluar la eficiencia de la red actual frente a la red de bus urbano y corroborar con datos cuantitativos la viabilidad de implementar la propuesta que se plantea.

\subsection{Antecedentes}

Las obras del carril bici de Alcalá de Henares se iniciaron en el año 2009 con la financiación de los fondos del Plan E. Dicho plan fue aprobado a través de Real Decreto-ley 9/2008 por el Gobierno de la Nación, y suponía la ejecución de una serie de medidas económicas con el objetivo de hacer frente a la crisis estimulando el crecimiento de empleo a través de la inversión de cantidades ingentes de dinero público. Se trataba pues, de "aumentar la inversión pública en el ámbito local, mediante la financiación de obras de nueva planificación, ejecución inmediata y competencia propia de las entidades locales""1.

Por lo que respecta a las normas o recomendaciones para el diseño de carriles bici que garanticen la seguridad vial y su correcta integración en el territorio, se podría comenzar haciendo mención de la LEY 19/2001, de reforma del texto articulado de la Ley de Tráfico, que introduce nuevas definiciones de los distintos tipos de ciclovías, ofrece algunos consejos y establece normas de seguridad vial para evitar conflictos entre vehículos motorizados y no motorizados. Esta iniciativa vino motivada por el uso cada vez más generalizado de bicicletas como medio alternativo de transporte, supuso un primer intento de reducir los accidentes de tráfico en el que estuviesen implicadas las bicicletas pero sin entrar de lleno en el establecimiento de unas directrices sobre cómo hacer un carril bici seguro, aunque más tarde serviría de preludio para ello. A raíz de estas modificaciones y con ánimo de hacer cumplir dichas leyes de seguridad, la D.G.T. elaboró un manual en el que se establecían una serie de pautas orientativas y criterios generales sobre la correcta implantación de un carril bici coherente y seguro con el objetivo de ayudar a técnicos de diferentes disciplinas que fueran a trabajar en la proyección y elaboración de este tipo de infraestructuras ${ }^{2}$.

Por su parte, el Ayuntamiento de Madrid (institución administrativa de gran influencia para Alcalá de Henares) elaboró su propio Plan Director Ciclista en 2010, un año después de iniciarse las obras del carril bici, el cual aporta unos criterios de cómo trazar los recorridos, establece una serie de normas de seguridad, define unos principios ambientales que justifican el uso de la bicicleta e incluye un inventario de las deficiencias y posibles mejoras de toda la red

\footnotetext{
${ }^{1}$ Fuente: https://www.boe.es/diario boe/txt.php?id=BOE-A-2009-17001 consultada el 10/08/2016

${ }^{2}$ Fuente: http://alcalaenbici.blogspot.com.es/2015/03/carril-bici-una-cuestion-de-voluntad.html consultada el $15 / 07 / 2016$
} 
Núñez Lucena, J.J. (2018): "Propuesta de catálogo normalizado de objetos aeronáuticos para el Ecuador", GeoFocus (Artículos), no 22, p. 43-70. ISSN: 1578-5157 http://dx.doi.org/10.21138/GF.605

de carril bici desglosada por tramos ${ }^{3}$. El Plan Director Ciclista de Madrid aporta una base teórica ejemplar en lo que se refiere a la orientación de la proyección y construcción de carriles bici ya que se ajusta a las normas de la D.G.T. y la Ley de Seguridad Vial aprobada en las Cortes.

También se pueden encontrar otros trabajos de gran influencia en el marco europeo e internacional como es el "Manual de Diseño para el Tráfico de Bicicletas" elaborado en el año 2006 por CROW (la plataforma nacional holandesa de conocimientos para el espacio de infraestructura, tráfico y transporte público). Este manual recoge una serie de orientaciones clave para lograr que la bicicleta ocupe un papel relevante entre los medios de transporte convencionales. Un aporte importante, y a ello se debe su marcada influencia en el contexto internacional, es la amplitud de conceptos y lo completa que es la obra en cuanto a orientaciones de diversa índole para la construcción de ciclo vías: normas de tráfico, gestión, intersecciones, diseño de la infraestructura, etc. Además de la ejemplar agrupación en ejes temáticos que dispone. Supondrá de gran apoyo para el presente trabajo debido a la excelente compilación de criterios para proveer de coherencia a una red de carril bici que aglutina en un mismo punto.

Por otra parte, un proyecto de movilidad de similares características, encargado por el Ayuntamiento de Alcalá de Henares al Departamento de Geología, Geografía y Medio Ambiente de la UAH, sirvió de fuente de inspiración para la elaboración del presente proyecto. Éste consistía en una reestructuración de los recorridos de las distintas líneas del bus urbano de Alcalá de Henares. La reestructuración se hacía necesaria debido a que la red actual dispone de un carácter radiocéntrico que impide la buena comunicación entre los barrios periféricos y a la vez congestiona el centro de tráfico. Para ello se emplearon herramientas de análisis de redes y procedimientos que han servido, en parte, como hoja de ruta para realizar el presente trabajo. Además los resultados obetenidos de analizar los tiempos de la red propuesta de bus urbano, han servido también para compararlos con los tiempos resultantes del análisis del carril bici (actual y propuesto) y de este modo conocer su eficiencia frente al transporte público urbano. (Osorio, 2015)

\section{Metodología y marco geográfico}

\subsection{Metodología.}

Desde el punto de vista metodológico, este trabajo ha requerido una recopilación de fuentes bibliográficas relacionadas con la temática, así como un estudio previo de la misma para la definición de los conceptos y la información descrita en la catalogación de los distintos tipos de ciclo vías, la cual se ha elaborado atendiendo a los patrones que establece el "Manual de Recomendaciones de Diseño para Vías Ciclistas de Andalucía"4 y la "Guía ciclista de Madrid" del Ayuntamiento de Madrid.

\footnotetext{
${ }^{3}$ Fuente: http://www.madrid.es/portales/munimadrid/es/Inicio/Vivienda-y-urbanismo/Publicaciones/Plan-Directorde-Movilidad-

Ciclista?vgnextfmt=default\&vgnextoid=09bccea83e67a110VgnVCM2000000c205a0aRCRD\&vgnextchannel=cf603 1d3b28fe410VgnVCM1000000b205a0aRCRD consultada el 15/07/2016

${ }^{4}$ Fuente:http://www.juntadeandalucia.es/fomentoyvivienda/estaticas/sites/consejeria/areas/transportes_infraestructura s/plan_bici/documentos_plan_bici/recomendaciones_diseno_vias_ciclistas.pdf consultada el 01/09/2016

${ }^{5}$ Fuente:http://www.madrid.es/UnidadesDescentralizadas/Educacion_Ambiental/ContenidosBasicos/Publicaciones/gu iaCiclistaMadrid/GUIA_CICLISTA_MADRID_EDICION2Sep13.pdf consultada el 01/09/2016
} 
Núñez Lucena, J.J. (2018): "Propuesta de catálogo normalizado de objetos aeronáuticos para el Ecuador", GeoFocus (Artículos), no 22, p. 43-70. ISSN: 1578-5157 http://dx.doi.org/10.21138/GF.605

En lo que se refiere al caso de estudio, se ha procedido a la elaboración de una cartografía específica, empleando las fuentes cartográficas de la Infraestructura de Datos Espaciales de CartoCiudad, dada la disponibilidad de este callejero y la posibilidad de configurarlo de forma sencilla como una red (análisis de redes) así como la ausencia de una cartografía oficial en formato shapefile. Se ha comenzado por digitalizar la red actual tomando como referencia la cartografía oficial puesta a disposición en la web del Ayuntamiento de Alcalá de Henares en formato PDF, elaborada por la Consejería Delegada de Medio Ambiente. Una vez digitalizada la cartografía oficial (para disponer de ella en formato shapefile), se ha requerido una revisión y actualización de la misma sobre datos tomados en campo, dado que algunos tramos existentes en dicha cartografía no existen en la realidad, así como otros trazados existentes que no están contemplados. Tras el análisis de la red actual, completa y revisada, se procedió de forma similar a crear la red propuesta. (Ver figura 1)

Para el tratamiento de los datos, se ha utilizado el SIG ArcGis 10.2.2., proyectando en primer lugar todas las capas en el sistema de coordenadas ETRS 1989 UTM Zone 30N. Dado que la pretensión del estudio es lanzar una propuesta alternativa al carril bici actual y llevar a cabo un análisis de comparación de tiempos de recorrido entre la red de carril bici actual y la red propuesta para comprobar su eficiencia en términos de tiempo. Se ha creado posteriormente un campo llamado "Minutos" donde se ha calculado la impedancia, es decir, el costo de llevar un recurso de un extremo del segmento al otro extremo, empleando la siguiente fórmula:

$$
\operatorname{Impedancia}(\min .)=\frac{\operatorname{Longitud}(\mathrm{m}) * 0,06}{\operatorname{Velocidad}(\mathrm{km} / \mathrm{h})}
$$

Para ello ha sido necesario calcular la longitud de cada segmento, tanto en el shapefile correspondiente al viario peatonal como en el de la red actual y la propuesta, creando un campo llamado "Shape_length" y seleccionando la opción "Calculate geometry". También ha sido necesaria la creación de un segundo campo para incluir la velocidad, rellenando todos los campos con lo siguiente:

- Para el viario peatonal $4 \mathbf{k m} / \mathbf{h}$. Considerando que es la velocidad promedio de una persona adulta que camina por una ciudad.

- Para el carril actual y propuesto $13 \mathrm{~km} / \mathrm{h}$. Como referencia un estudio llevado a cabo en Amsterdam donde la velocidad de crucero de las bicicletas que circulaban sobre el carril bici se constató que era de $18 \mathrm{~km} / \mathrm{h}$. Teniendo en cuenta que las característica del pavimento y la morfología urbana de Alcalá de Henares no son las mismas que las de Ámsterdam y pueden influir negativamente en la circulación normal de un ciclo, se ha reducido a $13 \mathrm{~km} / \mathrm{h}$ como una media estimada, presuponiendo que habrá tramos donde los usuarios vayan a mayor o menor velocidad y teniendo en cuenta que la duración de los recorridos son de media distancia, contando con una media de 15 minutos. Además se ha considerado únicamente aquellos usuarios que emplearían el carril como medio de desplazamiento alternativo entre un punto y otro de la ciudad, excluyendo de esta forma a aquellos que darían un uso deportivo al mismo. (Crow, 2011, 45) 


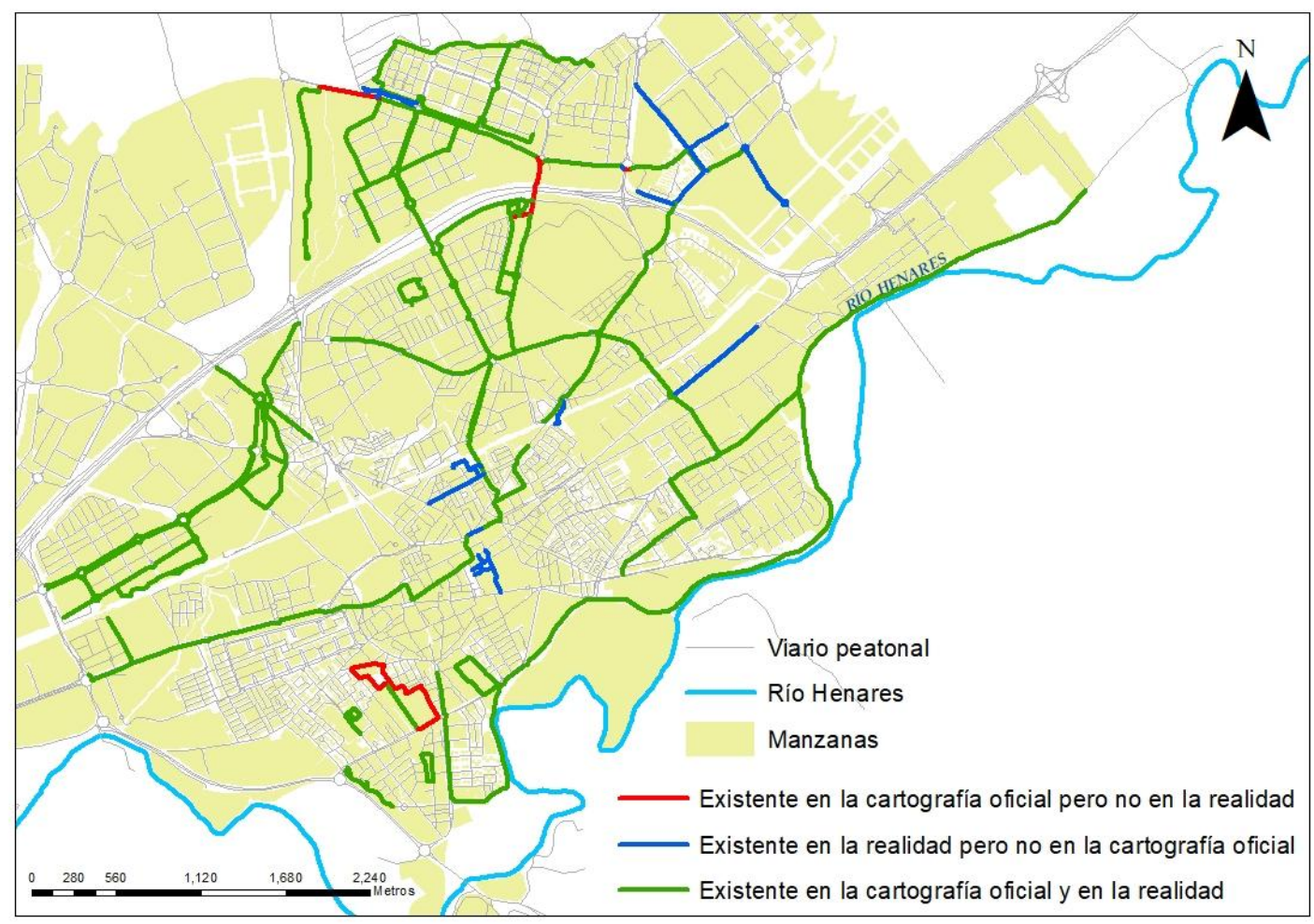

Figura 1: mapa de la actualización de la cartografía oficial de la red de carril bici de Alcalá de Henares.

Fuente: elaboración propia en base a los datos tomados en campo y los datos de Cartociudad.

A continuación se han creado dos geodatabases por separado (una para la red actual y otra para la red propuesta). Dentro de cada geodatabase se ha creado un Feature Dataset, que es un elemento cuya función es almacenar grupos de datos con el mismo sistema de referencia y coincidentes con una misma temática, lo cual resulta muy útil para tener la información ordenada. Además se ha incluido en cada Feature Dataset un Network Dataset para la modelación de una red y así poder utilizar las herramientas de análisis de red (Network Analyst) para la obtención de datos cuantitativos que permitan analizar la eficiencia de ambas redes en términos de tiempo. Conectando de este modo, durante el proceso de configuración: El viario peatonal con los centroides correspondientes a las secciones censales, los puntos de interés y los aparca-bicis, y con éste último el carril bici. Cabe aclarar que no se han configurado pasos elevados ni giros por considerarse irrelevante para el caso de estudio ya que no tendría repercusión en los resultados.

Una vez modeladas ambas redes (por separado), se han establecido las reglas topológicas pertinentes para comprobar que todos los elementos que la red incluye permanecen interconectados debidamente y no existen errores que puedan alterar los resultados. Es imprescindible comprobar la topología para proseguir con un proyecto de redes pues en caso de existir algún tipo de error podría influir en los resultados e incluso impedir el uso de las herramientas de análisis de redes. Para la selección de las reglas topológicas adecuadas, se debe tener en cuenta que se trata de una red multimodal (que permite tanto el movimiento a pie, en el viario peatonal, como en bicicleta, en el carril, con un conjunto de aparcamientos de bici). Cada uno de los segmentos del carril bici deben permanecer conectados con los aparca-bicis y éstos a su vez deberán conectar con el viario peatonal. Por ello se han empleado las siguientes reglas topológicas: 
Núñez Lucena, J.J. (2018): "Propuesta de catálogo normalizado de objetos aeronáuticos para el Ecuador", GeoFocus (Artículos), no 22, p. 43-70. ISSN: 1578-5157 http://dx.doi.org/10.21138/GF.605

- Point must be covered by line: para analizar la conectividad de los segmentos correspondientes al carril bici y también al viario con los aparca-bicis.

- Must be covered by feature class of: para analizar la conectividad de los segmentos correspondientes al viario con los correspondientes al carril bici.

Una vez se ha comprobado que no existen errores de topología y que la red funciona correctamente, se han establecido, con la herramienta New Route, una serie de rutas al azar entre zonas periféricas y entre zonas de la periferia y el centro urbano, cuyos resultados han sido comparados posteriormente. No obstante, el análisis donde recae el mayor peso del proyecto es en la creación de una Matriz de Orígenes y Destinos, en la que se han seleccionado, como puntos de partida, los centroides correspondientes a cada una de las secciones censales y, como puntos de destino, aquellos lugares que presentan una mayor capacidad de atracción en el municipio de Alcalá de Henares (los cuales se describen más adelante). Los resultados obtenidos de ambas matrices (red actual y propuesta), han sido manipulados con Microsoft Excel para calcular la diferencia de los totales de tiempos empleados y se le ha otorgado a la matriz una estructura adecuada con un script de RStudio, obteniendo como resultado aquellos recorridos que mejoran sus tiempos, pierden o se mantienen estáticos en la red propuesta respecto a la red actual. También con Microsoft Excel se han calculado algunos datos estadísticos como máximos, mínimos o promedio, que han sido de utilidad para ordenar los datos y crear un gráfico de barras, que sea representativo de la matriz, así como su inclusión en el texto.

Puesto que se disponía de los resultados de un mismo análisis previo llevado a cabo a petición del Ayuntamiento de Alcalá de Henares en el que se comparaban los tiempos de la red actual de bus urbano con los de una propuesta, se han aprovechado los resultados para su comparación con los de la red actual y propuesta del carril bici. De este modo se ha pretendido conocer en qué medida sería más eficiente el uso de la bicicleta en la ciudad y su viabilidad como medio de transporte alternativo.

Además de comprobar la eficiencia de la red de carril bici actual y propuesta con las herramientas de análisis que se han mencionado, también se ha llevado a cabo una evaluación de la seguridad del carril bici actual teniendo en cuenta: por un lado la intersección con peatones y otros vehículos motorizados, y por otro lado comprobando si la anchura de los carriles cumplen con la normativa de seguridad de la DGT.

Para comprobar la seguridad del carril teniendo en cuenta la intersección con peatones y vehículos motorizados, se ha realizado una catalogación de las vías teniendo en cuenta el tipo de carril. Por lo que se ha establecido una nomenclatura y se han otorgado valores más altos a aquellos carriles que están en su totalidad o mayormente segregados de otros tráficos motorizados y peatones (pista-bici, carril-bici protegido, acera-bici y carril-bici) mientras que aquellos carriles cuya interferencia es mayor se les han atribuido valores más bajos (vía compartida interurbana, vía para peatones y ciclos, calles peatonales y ciclocalles).

En cuanto a la seguridad de las vías según su ancho, se ha procedido a una revisión bibliográfica para tener como referencia la anchura que otros planes rectores o la misma DGT aconsejan para velar por la seguridad de los usuarios. El establecimiento de la anchura recomendada por el presente trabajo se ha llevado a cabo en función del tipo de carril según las indicaciones de la $\mathrm{DGT}^{6}$. Coincidiendo con una mayor anchura recomendada aquellos carriles que presentan una menor segregación del tráfico rodado y peatonal mientras que aquellos

\footnotetext{
${ }^{6}$ Fuente: https://ciudadanabicicleta.files.wordpress.com/2012/01/manual-dgt-2000-disec3b1o.pdf consultada $01 / 09 / 2016$
} 
Núñez Lucena, J.J. (2018): "Propuesta de catálogo normalizado de objetos aeronáuticos para el Ecuador", GeoFocus (Artículos), no 22, p. 43-70. ISSN: 1578-5157 http://dx.doi.org/10.21138/GF.605

carriles que presentan una mayor segregación respecto a otros tráficos requieren una menor anchura ya que el "espacio vital" de los usuarios no se ve alterado por la presencia de otros vehículos. Posteriormente se ha creado una nomenclatura para evaluar los carriles que cumplen con la normativa y los que no: Por debajo del mínimo $=0,1$; Valor mínimo $=0,4$; Valor medio $=0,7$; Valor máximo o superior $=1$.

Para ambas catalogaciones se ha creado un nuevo campo de tipo texto en la tabla de atributos del shapefile correspondiente al carril y se han rellenado los campos (correspondientes a los segmentos que representan las vías del carril) con los valores mencionados. Cabe destacar la importancia que ha tenido el campo "Shape_length" para obtener información de la cantidad de kilómetros de carril que cuentan con una determinada catalogación, la cual se ha obtenido a través de consultas SQL con la herramienta "Select by Attributes". A posteriori se han exportado las tablas con los atributos seleccionados (con la opción "Export Data") y se han sumado los campos con Microsoft Excel. De estar realizando un proyecto que cuente con mucha información y mayor cantidad de tablas, otra opción que quizá ahorraría mucho tiempo sería guardar las tablas en una base de datos y realizar consultas específicas con lenguaje SQL y de este modo evitar todo el proceso llevado a cabo que puede resultar muy farragoso.

Finalmente, los resultados obtenidos han sido de utilidad para establecer una hipótesis de la poca aceptación que ha tenido la red actual de carril bici en Alcalá de Henares y buscar alternativas que solventen el problema. Asimismo, los datos se han empleado para tener una noción cuantitativa de la eficiencia de una red respecto a la otra y se han comentado de forma apropiada, dando lugar a la elaboración de unas conclusiones generales.

\subsection{Marco geográfico.}

El municipio de Alcalá de Henares, integrado en el Área Metropolitana de Madrid, se encuentra situado en el centro del Estado español, asentado sobre el Corredor del Henares; su término municipal limita con la provincia de Guadalajara (Castilla La Mancha). Su superficie es de $87.72 \mathrm{~km}^{2}$ y cuenta con una población total de 198.750 habitantes en el año 2015 según datos del INE (Instituto Nacional de Estadística) por lo que la densidad poblacional es de $2.266 \mathrm{hab} . / \mathrm{km}^{2}$. 
Núñez Lucena, J.J. (2018): "Propuesta de catálogo normalizado de objetos aeronáuticos para el Ecuador", GeoFocus (Artículos), no 22, p. 43-70. ISSN: 1578-5157 http://dx.doi.org/10.21138/GF.605
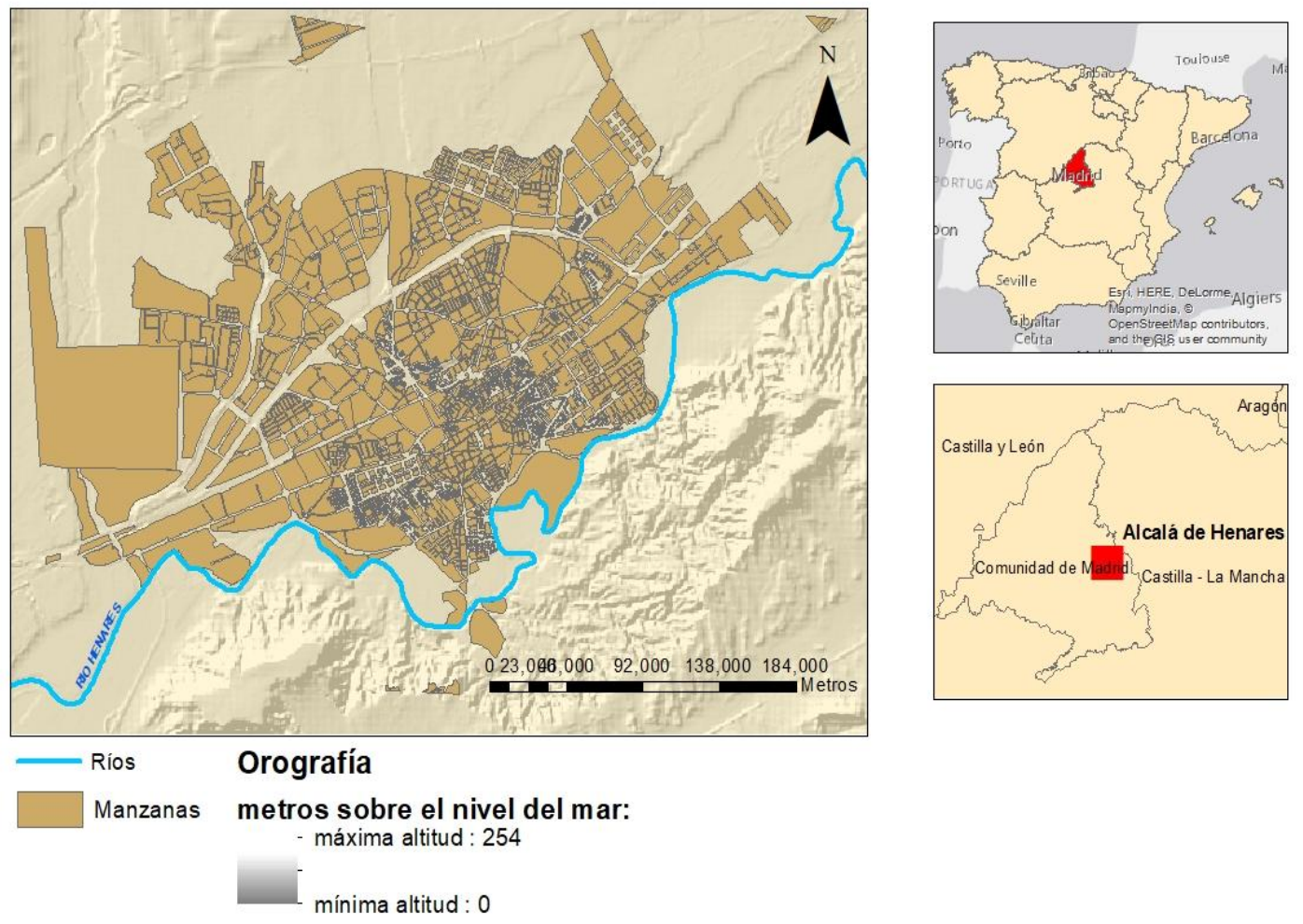

Figura 2: Mapa de localización de Alcalá de Henares.

Fuente: elaboración propia en base a los datos de Cartociudad

\section{Resultados y discusión.}

3.1. Situación actual de la red de carril bici de Alcalá de Henares (Madrid).

La red actual de carril bici de Alcalá de Henares cuenta con un total de 57 kilómetros y medio aproximadamente según el resultado de los datos que han sido generados para la elaboración del presente trabajo. Ésta es una cifra muy significativa si la comparamos con la ciudad de Sevilla, la cual ha pasado de contar en 2003 con 12 kilómetros de ciclo vías inconexas y de poca utilidad práctica, a contar en 2010 con un total de 120 kilómetros de carriles bici bidireccionales. Aunque la cifra expuesta, a priori, parece quedar lejos de los $120 \mathrm{~km}$. Sevilla, se puede decir que es significativa si tenemos en cuenta que Alcalá de Henares es una ciudad de 200.000 habitantes frente a la capital andaluza que aglutina un total de 700.000 habitantes (sin contar el conjunto de su área metropolitana). (Marqués, 2011, 110)

A pesar de la importancia de la cifra que se ha mencionado hay que valorar algunos aspectos a tener en cuenta como la conectividad de esos kilómetros o la calidad de los tramos para conocer su utilidad como medio de transporte dentro del casco urbano. Como ya se ha mencionado reiteradas veces el carril bici de Alcalá de Henares presenta algunos problemas de suma importancia como la falta de conectividad o el pésimo estado del pavimento que influyen de forma negativa en su eficiencia. 
Núñez Lucena, J.J. (2018): "Propuesta de catálogo normalizado de objetos aeronáuticos para el Ecuador", GeoFocus (Artículos), no 22, p. 43-70. ISSN: 1578-5157 http://dx.doi.org/10.21138/GF.605

\subsection{Tipología de ciclo vías existentes en la red actual.}

Para la clasificación de ciclo vías de la red actual se han detectado un total de 8 tipos diferentes los cuales se engloban en dos categorías diferenciadas: carriles periurbanos y carriles urbanos. Dicha clasificación se ha realizado tomando como referencia las "Recomendaciones de diseño para las vías ciclistas en Andalucía" de la Consejería de Fomento y Vivienda por un lado, y el "Manual de convivencia entre coche y bicicleta" elaborado por el Área de Gobierno de Medio Ambiente y Movilidad de Madrid por otro. Es muy importante tener en cuenta que a pesar de haber establecido unos criterios para la clasificación de las ciclo vías en base a unas fuentes de referencia, los tipos de vías ciclistas clasificadas se definen en función de su uso preferente y su relación con otros vehículos motorizados. (Junta de Andalucía, 2013, 6-8)

A continuación se procederá a la realización de una descripción de los diferentes tipos de ciclovías detectadas y de este modo poder tener una visión más clara de las características cuando se haga referencia a un tipo de carril u otro:

a) Carriles periurbanos. Como su propio nombre indica esta categoría, aglutina todos aquellos carriles que discurren por aquellas zonas alejadas del casco urbano propiamente dicho y que se consideran de tránsito entre la ciudad y el entorno rural:

- Pista-bici: engloba aquellos carriles segregados del tráfico motorizado e independientes de la calzada.

- Vía compartida interurbana: son aquellas vías que discurren por zonas rurales y coexiste el tráfico ocasional motorizado y no motorizado.

- Ciclo-senda: es un carril compartido con peatones y segregado del tráfico de vehículos motorizados. Discurren por parques, jardines o bosques.

b) Carriles urbanos. En esta categoría se localizan aquellas ciclovías que se extienden sobre el espacio urbano y a las cuales se les consideran como realmente útiles para los desplazamientos que no tienen que ver con el ocio y permitan por lo tanto utilizar los ciclos como transporte alternativo a los vehículos motorizados convencionales:

- Carril-bici protegido: aquellas vías que discurren adosadas a la calzada y están dotadas de barreras u otros elementos de protección que las separan físicamente del tráfico motorizado.

- Carril-bici no protegido: aquellas vías que discurren adosadas a la calzada y que no disponen de elementos que la separe físicamente del tráfico motorizado.

- Acera-bici: vías que discurren sobre la acera y que cuentan con señalización.

- Calles peatonales ciclables: son aquellas calles peatonales donde se está permitido el tránsito de ciclos con prioridad para peatones.

- Ciclocalle: aquellas calles que, cumpliendo con la normativa, son compartidas por vehículos motorizados y ciclos. 
Núñez Lucena, J.J. (2018): "Propuesta de catálogo normalizado de objetos aeronáuticos para el Ecuador", GeoFocus (Artículos), no 22, p. 43-70. ISSN: 1578-5157 http://dx.doi.org/10.21138/GF.605

Una vez descritos cada uno de los tipos de vía detectados se muestra la siguiente tabla a modo de resumen donde además aparece la extensión en kilómetros para una mayor información:

Tabla 1: Cuadro de tipología de ciclovías.

\begin{tabular}{|c|lc|}
\hline \multicolumn{2}{|c|}{ Tipología de ciclovías en la red actual de Alcalá de Henares } \\
\hline \multicolumn{1}{|c|}{ Categorías } & \multicolumn{1}{c|}{ Tipos } & Extensión en km \\
\hline Carriles periurbanos & Pista-bici & 2.42 \\
\cline { 2 - 3 } & $\begin{array}{l}\text { Vía compartida } \\
\text { interurbana }\end{array}$ & 1.82 \\
\cline { 2 - 3 } & Ciclo-senda & 14.94 \\
\hline \multirow{5}{*}{ Carriles urbanos } & Carril-bici protegido & 0.08 \\
\cline { 2 - 3 } & Carril-bici no protegido & 1.66 \\
\cline { 2 - 3 } & Acera-bici & 33.60 \\
\cline { 2 - 3 } & $\begin{array}{l}\text { Calles peatonales } \\
\text { ciclables }\end{array}$ & 1.44 \\
\cline { 2 - 3 } & Ciclocalle & 1.24 \\
\hline & Total & $\mathbf{5 7 . 2 0}$ \\
\hline
\end{tabular}

Fuente. Elaboración propia en base al manual "Recomendaciones de diseño para las vías ciclistas en Andalucía" y el "Manual de convivencia entre coche y bicicleta"

Como se puede observar, la red actual cuenta con una extensión total de 19.18 kilómetros de carriles periurbanos frente a 38.02 kilómetros de carriles urbanos. En cuanto a la extensión, los datos son favorables debido a que la mayoría de los tramos son útiles para los trayectos cotidianos como ir al trabajo, a la Universidad u otros desplazamientos de corta distancia dentro del núcleo urbano. Además la acera-bici, que se considerará como la más idónea para este tipo de desplazamientos, destaca notablemente dentro de su propia categoría e incluso cuenta con mayor extensión que el conjunto de la subcategoría de carriles periurbanos.

Se considerará la acera-bici ideal para este tipo de desplazamientos debido a que, a pesar de la cantidad de problemas de seguridad y ventajas que presentan todos y cada uno de los tipos de carril, la acera-bici, aunque es invadida por los peatones en determinadas ocasiones, aísla en mayor medida al ciclista del tráfico rodado. Una alternativa reciente a la acera-bici han sido unos carriles integrados en la calzada pero separados de vehículos motorizados. No obstante al discurrir por el lado izquierdo de la calle, los ciclistas se ven afectados por coches que aparcan en doble fila y sufren el riesgo de tener un accidente cuando abren la puerta, además los peatones suelen cruzar indebidamente por medio del carril igualmente. Por otro lado las calles compartidas limitadas a $30 \mathrm{~km}$ también ponen en riesgo al ciclista de colisionar con un vehículo motorizado por lo que teniendo presente todos estos argumentos, la acera-bici cuenta con un riesgo menor para el ciclista de sufrir accidentes de gravedad. ${ }^{7}$

A pesar de ello no se debe perder de vista que la extensión de carriles periurbanos supone un $33 \%$ del total de la red actual, lo que supone una cifra relativamente elevada. Además, se debe tener en cuenta que la deficiente calidad del pavimento y la falta de conectividad en muchos tramos de los carriles urbanos condiciona de forma negativa su eficiencia. Por ello en el siguiente apartado se mostrará un mapa de los diferentes tipos de ciclo vías existentes y se

\footnotetext{
${ }^{7}$ Fuente: https://www.20minutos.es/noticia/3288906/0/tipos-carriles-bici-ventas-inconvenientes/ consultada $15 / 06 / 2018$
} 
Núñez Lucena, J.J. (2018): "Propuesta de catálogo normalizado de objetos aeronáuticos para el Ecuador", GeoFocus (Artículos), no 22, p. 43-70. ISSN: 1578-5157 http://dx.doi.org/10.21138/GF.605

describirán las características físicas de la red con el objetivo de poder realizar una valoración más exhaustiva de la calidad general de la misma.

\subsection{Estructura de la red actual de carril-bici.}

La estructura de la red guarda una estrecha relación con la coherencia. Para el establecimiento de unos criterios de coherencia en este trabajo se considerarán tres aspectos básicos, basados en la literatura revisada; al menos los dos primeros son considerados mayoritariamente como condición sine qua non para que una red sea considerada como tal:

a) No debe existir la presencia de tramos aislados o que la mayoría de los recorridos no tengan continuidad, con el objetivo de garantizar la interconexión.

b) La red de carril-bici debe garantizar la conexión, lo más directa posible, entre los puntos de origen y los puntos de destino. (DGT, 2000, p.1)

c) También deberá asegurar su conexión con otras redes viales (tren de cercanías o paradas de bus) a fin de facilitar y promover la intermodalidad del transporte. En este sentido se pretende que la red de carril bici contribuya a la eficiencia del transporte permitiendo acortar el tiempo de los itinerarios y mejorar la accesibilidad entre los puntos de origen y destino.

Teniendo en cuenta estos tres aspectos básicos que definirán la coherencia de la red en el presente trabajo, se podrá proseguir realizando una valoración de la situación actual y detectar las carencias a mejorar en la propuesta. En la siguiente página se puede observar un mapa de la red actual, donde además de los distintos tipos de ciclo vías detectadas, se puede apreciar con bastante claridad la estructura, distribución de aparcamientos de bici disponibles y su cobertura con los puntos de interés.

En una primera observación resalta el carácter inconexo de la estructura de la red y su falta de articulación en barrios como Juan de Austria o El Val (al suroeste) así como la falta de cobertura a algunos puntos de interés como el Centro de Especialidades, el apeadero de Cuadernillos y el centro comercial La Dehesa. A pesar de ello la única potencialidad que parece presentar la red es que da cobertura a los principales puntos de interés como el Casco Histórico, los diferentes polideportivos de la ciudad o la Universidad y el Hospital Príncipe de Asturias, pero ésta es más bien aparente ya que el carácter inconexo que presenta impide realizar trazados sin interrupción.

Para ratificar con datos cuantitativos la ineficiencia provocada por las características que se han mencionado en párrafo anterior, se han calculado una serie de rutas óptimas con la herramienta Network Analyst de ArcMap y se han comparado los tiempos empleados por el bus urbano y la bicicleta. A fin de ofrecer una mejor comprensión a quienes no estén familiarizados/as con el callejero de Alcalá de Henares, se mostrará una tabla previa en la que se muestra las distancias de las rutas y las coordenadas de origen y destino: 
Núñez Lucena, J.J. (2018): "Propuesta de catálogo normalizado de objetos aeronáuticos para el Ecuador", GeoFocus (Artículos), no 22, p. 43-70. ISSN: 1578-5157 http://dx.doi.org/10.21138/GF.605

Tabla 2: Cuadro de distancia de las rutas y coordenadas de origen y destino.

\begin{tabular}{|c|c|c|c|c|}
\hline \multicolumn{5}{|c|}{ Rutas periferia-centro } \\
\hline \multirow[b]{2}{*}{ Origen } & \multirow[b]{2}{*}{ Destino } & \multirow[b]{2}{*}{ istancia $(\mathrm{km})$} & \multicolumn{2}{|c|}{ Latitud y longitud } \\
\hline & & & Origen & Destino \\
\hline c/Cruz de San Sebastián & Plza. Cervantes & 4 & $\begin{array}{r}40^{\circ} 30^{\prime} 28.63^{\prime \prime} \mathrm{N} \\
3^{\circ} 20^{\prime} 36.04^{\prime \prime} \mathrm{O}\end{array}$ & $\begin{array}{r}40^{\circ} 28^{\prime} 56.15^{\prime \prime} \mathrm{N} \\
3^{\circ} 21^{\prime} 47.48^{\prime \prime} \mathrm{O}\end{array}$ \\
\hline c/Miguel Hernández & c/Sebastián de la P.za & 2.7 & $\begin{array}{r}40^{\circ} 30^{\prime} 26.38^{\prime \prime} \mathrm{N} \\
3^{\circ} 22^{\prime} 4.72^{\prime \prime} \mathrm{O} \\
\end{array}$ & $\begin{array}{l}40^{\circ} 29^{\prime} 9.62^{\prime \prime} \mathrm{N} \\
3^{\circ} 21^{\prime} 43.66^{\prime \prime} \mathrm{O} \\
\end{array}$ \\
\hline c/Ávila & c/Colegios & 2.18 & $\begin{array}{r}40^{\circ} 29^{\prime} 25.97 " \mathrm{~N} \\
3^{\circ} 20^{\prime} 43.05^{\prime \prime} \mathrm{O}\end{array}$ & $\begin{array}{r}40^{\circ} 28^{\prime} 52.74 " \mathrm{~N} \\
3^{\circ} 21^{\prime} 49.45^{\prime \prime} \mathrm{O}\end{array}$ \\
\hline Av. Reyes Católicos & Plza. Cervantes & 1.5 & $\begin{array}{r}40^{\circ} 28^{\prime} 23.58^{\prime \prime} \mathrm{N} \\
3^{\circ} 22^{\prime} 45.96^{\prime \prime} \mathrm{O}\end{array}$ & $\begin{array}{r}40^{\circ} 28^{\prime} 56.15^{\prime \prime} \mathrm{N} \\
3^{\circ} 21^{\prime} 47.48^{\prime \prime} \mathrm{O}\end{array}$ \\
\hline c/San Ignacio Loyola & c/Sebastián de la P.za & 1.4 & $\begin{array}{r}40^{\circ} 29^{\prime} 26.71 " \mathrm{~N} \\
3^{\circ} 22^{\prime} 24.89^{\prime \prime} \mathrm{O} \\
\end{array}$ & $\begin{array}{l}40^{\circ} 29^{\prime} 9.62^{\prime \prime} \mathrm{N} \\
3^{\circ} 21^{\prime} 43.66^{\prime \prime} \mathrm{O} \\
\end{array}$ \\
\hline c/Fuente del Sol & Plza. Cervantes & 2 & $\begin{array}{r}40^{\circ} 28^{\prime} 13.53^{\prime \prime} \mathrm{N} \\
3^{\circ} 22^{\prime} 1.77 " \mathrm{O} \\
\end{array}$ & $\begin{array}{r}40^{\circ} 28^{\prime} 56.15 " \mathrm{~N} \\
3^{\circ} 21^{\prime} 47.48^{\prime \prime} \mathrm{O} \\
\end{array}$ \\
\hline C. Medio Ambiente & Plza. Cervantes & 2.7 & $\begin{array}{r}40^{\circ} 29^{\prime} 42.66^{\prime \prime} \mathrm{N} \\
3^{\circ} 20^{\prime} 43.96 " \mathrm{O}\end{array}$ & $\begin{array}{r}40^{\circ} 28^{\prime} 56.15 " \mathrm{~N} \\
3^{\circ} 21^{\prime} 47.48^{\prime \prime} \mathrm{O}\end{array}$ \\
\hline \multicolumn{5}{|c|}{ Periferia-periferia } \\
\hline c/Cruz de San Sebastian & c/José Ruíz Azorín & 2 & $\begin{array}{l}40^{\circ} 29^{\prime} 9.62^{\prime \prime} \mathrm{N} \\
3^{\circ} 21^{\prime} 43.66^{\prime \prime} \mathrm{O}\end{array}$ & $\begin{array}{r}40^{\circ} 30^{\prime} 25.10^{\prime \prime} \mathrm{N} \\
3^{\circ} 22^{\prime} 11.35^{\prime \prime} \mathrm{O}\end{array}$ \\
\hline c/José Ruíz Azorín & c/Ávila & 3.5 & $\begin{array}{r}40^{\circ} 30^{\prime} 25.10^{\prime \prime} \mathrm{N} \\
3^{\circ} 22^{\prime} 11.35^{\prime \prime} \mathrm{O} \\
\end{array}$ & $\begin{array}{r}40^{\circ} 29^{\prime} 25.97 " \mathrm{~N} \\
3^{\circ} 20^{\prime} 43.05^{\prime \prime} \mathrm{O} \\
\end{array}$ \\
\hline c/Ávila & Av. Reyes Católicos & 3 & $\begin{array}{r}40^{\circ} 29^{\prime} 25.97 " \mathrm{~N} \\
3^{\circ} 20^{\prime} 43.05^{\prime \prime} \mathrm{O} \\
\end{array}$ & $\begin{array}{r}40^{\circ} 28^{\prime} 23.58^{\prime \prime} \mathrm{N} \\
3^{\circ} 22^{\prime} 45.96 " \mathrm{O} \\
\end{array}$ \\
\hline Av. Reyes Católicos & c/San Ignacio Loyola & 2 & $\begin{array}{r}40^{\circ} 28^{\prime} 23.58^{\prime \prime} \mathrm{N} \\
3^{\circ} 22^{\prime} 45.96^{\prime \prime} \mathrm{O} \\
\end{array}$ & $\begin{array}{r}40^{\circ} 29^{\prime} 26.97 " \mathrm{~N} \\
3^{\circ} 22^{\prime} 24.77^{\prime \prime O} \\
\end{array}$ \\
\hline c/San Ignacio Loyola & c/Fuente del Sol & 2.5 & $\begin{array}{r}40^{\circ} 29^{\prime} 26.97 " \mathrm{~N} \\
3^{\circ} 22^{\prime} 24.77^{\prime \prime} \mathrm{O} \\
\end{array}$ & $\begin{array}{r}40^{\circ} 28^{\prime} 13.53^{\prime \prime} \mathrm{N} \\
3^{\circ} 22^{\prime} 1.77^{\prime \prime O} \\
\end{array}$ \\
\hline c/Fuente del Sol & C. Medio Ambiente & 4 & $\begin{array}{r}40^{\circ} 28^{\prime} 13.53^{\prime \prime} \mathrm{N} \\
3^{\circ} 22^{\prime} 1.77^{\prime \prime} \mathrm{O} \\
\end{array}$ & $\begin{array}{r}40^{\circ} 29^{\prime} 42.66^{\prime \prime N} \\
3^{\circ} 20^{\prime} 43.96 " \mathrm{O} \\
\end{array}$ \\
\hline C. Medio Ambiente & c/ del Juncal & 3.8 & $\begin{array}{r}40^{\circ} 29^{\prime} 42.66^{\prime \prime} \mathrm{N} \\
3^{\circ} 20^{\prime} 43.96^{\prime \prime} \mathrm{O}\end{array}$ & $\begin{array}{r}40^{\circ} 28^{\prime} 31.55^{\prime \prime} \mathrm{N} \\
3^{\circ} 22^{\prime} 57.06^{\prime \prime} \mathrm{O}\end{array}$ \\
\hline
\end{tabular}

Fuente: elaboración propia en base los datos de Cartociudad. 
Núñez Lucena, J.J. (2018): "Propuesta de catálogo normalizado de objetos aeronáuticos para el Ecuador", GeoFocus (Artículos), no 22, p. 43-70. ISSN: 1578-5157 http://dx.doi.org/10.21138/GF.605

Tabla 3: Cuadro de comparación de tiempos entre el bus urbano y la red de carril bici actual.

\begin{tabular}{|llccc|}
\hline \multicolumn{2}{|c}{ Rutas periferia-centro } & Bus urbano & Carril bici actual & Diferencia \\
\hline Origen & Destino & minutos & minutos & minutos \\
\hline c/Cruz de San Sebastián & Plza. Cervantes & 18.31 & 21.78 & $\mathbf{- 3 . 4 7}$ \\
\hline c/Miguel Hernández & c/Sebastián de la P.za & 23.16 & 28.95 & $\mathbf{- 5 . 7 9}$ \\
\hline c/Ávila & c/Colegios & 18.7 & 21.71 & $\mathbf{- 3 . 0 1}$ \\
\hline Av. Reyes Católicos & Plza. Cervantes & 10.16 & 21.57 & $\mathbf{- 1 1 . 4 1}$ \\
\hline c/San Ignacio Loyola & c/Sebastián de la P.za & 9.78 & 19.27 & $\mathbf{- 9 . 4 9}$ \\
\hline c/Fuente del Sol & Plza. Cervantes & 11.54 & 27.06 & $\mathbf{- 1 5 . 5 2}$ \\
\hline C. Medio Ambiente & Plza. Cervantes & 17.54 & 19.65 & $\mathbf{- 2 . 1 1}$ \\
\hline & \multicolumn{2}{c}{ Periferia-periferia } & & \\
\hline c/Cruz de San Sebastian & c/José Ruíz Azorín & 20.45 & 17.55 & $\mathbf{2 . 9}$ \\
\hline c/José Ruíz Azorín & c/Ávila & 33.65 & 24.67 & $\mathbf{8 . 9 8}$ \\
\hline c/Ávila & Av. Reyes Católicos & 21.9 & 27.41 & $\mathbf{- 5 . 5 1}$ \\
\hline Av. Reyes Católicos & c/San Ignacio Loyola & 14.36 & 29.2 & $\mathbf{- 1 4 . 8 4}$ \\
\hline c/San Ignacio Loyola & c/Fuente del Sol & 23.29 & 35.67 & $\mathbf{- 1 2 . 3 8}$ \\
\hline c/Fuente del Sol & C. Medio Ambiente & 27.62 & 34.05 & $\mathbf{- 6 . 4 3}$ \\
\hline C. Medio Ambiente & c/ del Juncal & 25.9 & 46.66 & $\mathbf{- 2 0 . 7 6}$ \\
\hline
\end{tabular}

Fuente: elaboración propia en base los datos de Cartociudad.

Los datos arrojados reflejan una marcada ineficiencia del carril bici respecto al bus urbano tanto en trayectos entre la periferia como entre la periferia y el centro ya que los resultados del sumatorio de ambas pérdidas son -48.04 y -50.8 minutos respectivamente. Resaltan algunas pérdidas de 15 minutos e incluso de 20 entre la Vía Complutense y la Calle del Juncal. 


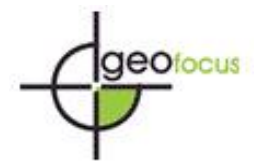

Núñez Lucena, J.J. (2018): "Propuesta de catálogo normalizado de objetos aeronáuticos para el Ecuador", GeoFocus (Artículos), no 22, p. 43-70. ISSN: 1578-5157 http://dx.doi.org/10.21138/GF.605

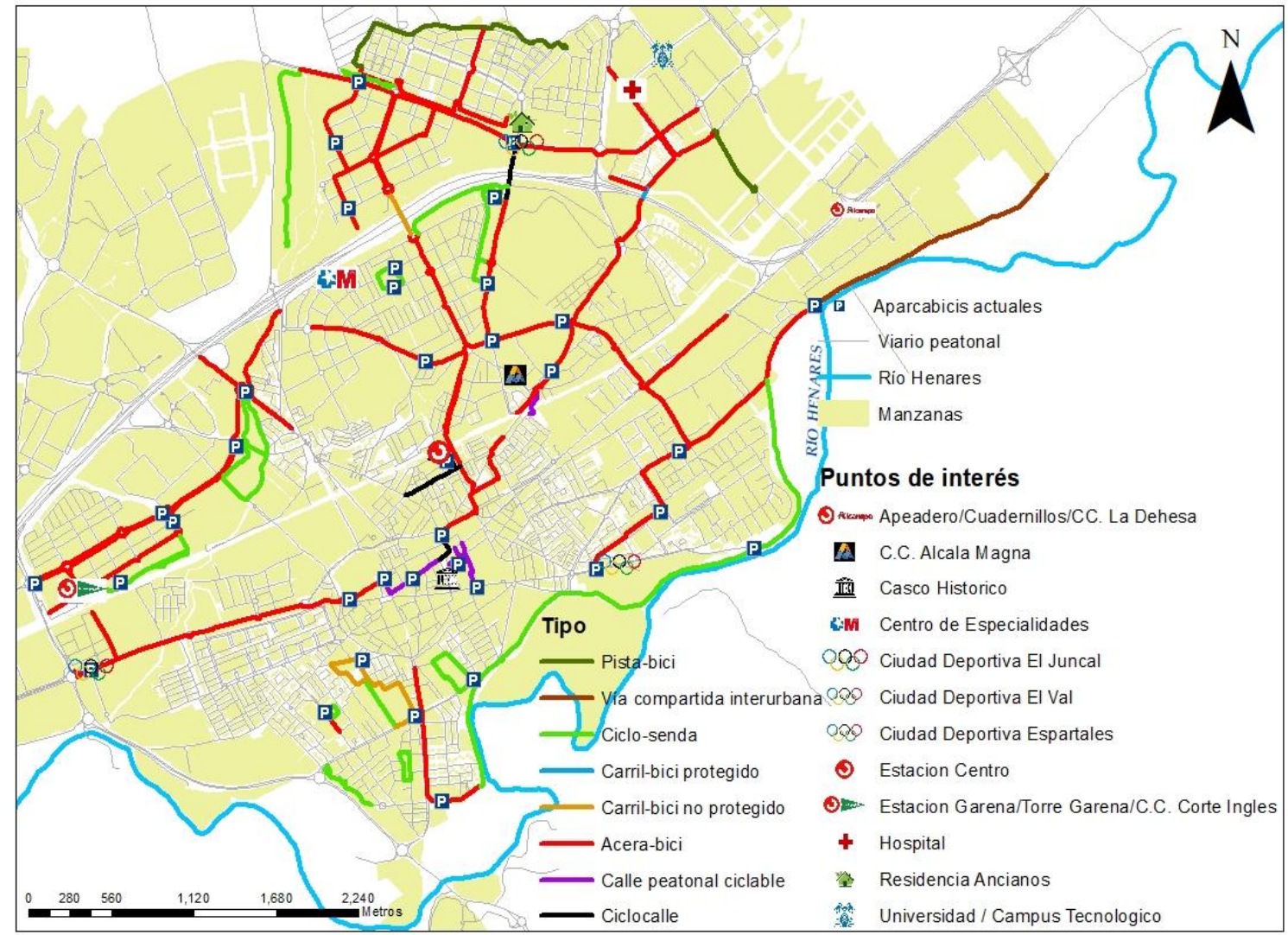

Figura 3: Mapa de tipología de ciclovías en la red de carril bici actual de Alcalá de Henares.

Fuente: elaboración propia en base a los datos de Cartociudad.

\subsection{Características físicas y seguridad de la red actual.}

En este apartado se procederá a valorar la seguridad de las ciclovías empleando como criterios la anchura de los tramos y la interferencia con otros vehículos motorizados o con peatones. Este aspecto influirá directamente en la calidad de la red así como en el tiempo empleado en los recorridos. La DGT y aquellos planes directores para el diseño de carriles bici que siguen sus parámetros, establecen una serie de normas y recomendaciones para velar por la seguridad de los usuarios. Entre las normas mencionadas destacan la estipulación de una anchura idónea para los distintos tipos de ciclo vías y una serie de normas de circulación para evitar accidentes con el tráfico motorizado. De este modo el Plan Director de la Bicicleta de Zaragoza por ejemplo, establece entre sus parámetros para el diseño de una vía ciclable que la intensidad del tráfico de vehículos motorizados y su velocidad influirá en la elección de las vías de coexistencia así como en el tipo de segregación del carril. (Ayto. Zaragoza, 2010, 3)

En cuanto a la anchura recomendada de las vías para valorar la red actual en este trabajo, se han considerado los criterios que la DGT establece por considerar que sus cálculos son más exactos y ser el referente por excelencia de todos los planes directores. La DGT establece que para definir la anchura del carril se deberá analizar "cuál es el espacio mínimo que necesita un ciclista para circular". Por lo que se tiene en cuenta que las dimensiones mínimas para el conjunto bicicleta-ciclista son: 
Núñez Lucena, J.J. (2018): "Propuesta de catálogo normalizado de objetos aeronáuticos para el Ecuador", GeoFocus (Artículos), no 22, p. 43-70. ISSN: 1578-5157 http://dx.doi.org/10.21138/GF.605

\section{Anchura: 0,75 m; Altura: 2,00 - 2,25 m; Longitud: 1,75 - 1,90 m; Distancias entre el suelo y pedal: $0,05 \mathrm{~m}$}

Además se debe tener en cuenta que el ancho mínimo estricto para la circulación de un ciclista es de $1 \mathrm{~m}$ y se recomienda un resguardo de $0,25 \mathrm{~m}$ a ambos lados por seguridad de posibles movimientos o el movimiento "serpenteante" para corregir la inestabilidad. Por ello, el ancho estricto necesario que la DGT establece en carriles unidireccionales es de $1,50 \mathrm{~m}$ mientras que para la circulación en paralelo "será la suma del que requiere cada uno más un resguardo de 0,25 m a ambos lados", sumando un total de 2,50 m. Pero en el caso de existir bordillos con una altura superior a los $0,05 \mathrm{~m}$, el resguardo pasaría a ser de $0,50 \mathrm{~m}$, elevando la anchura del carril a 3,00m. (DGT, 2000, pp. 6-7)
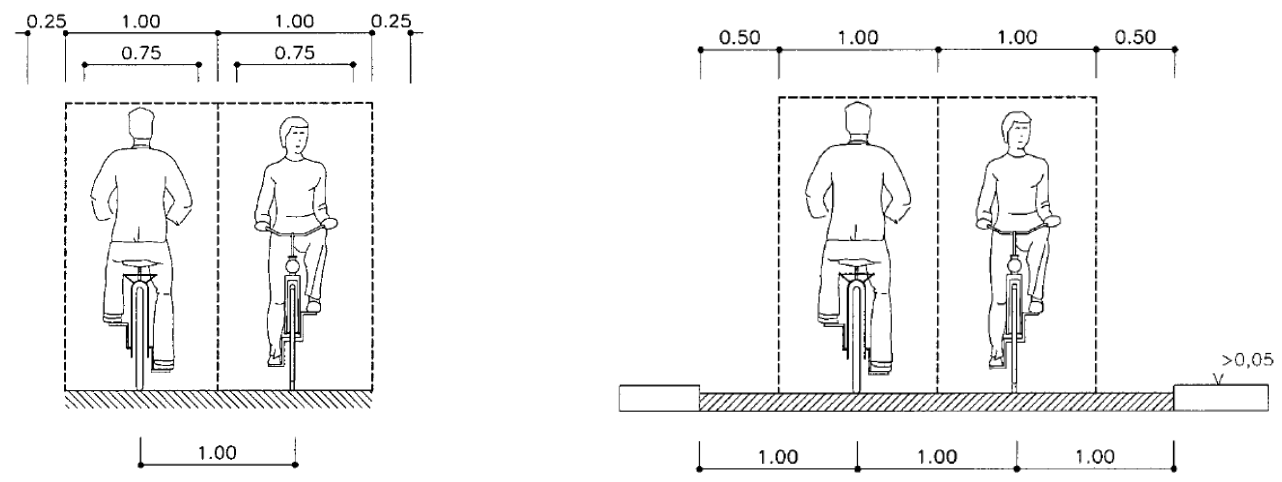

Figura 4: gálibo de un ciclista para carriles unidireccionales (izquierda) y para carriles bidireccionales (derecha).

Fuente:Dirección General de Tráfico (DGT, 2000, pp. 6-7)

Atendiendo a las indicaciones expuestas según los datos de la de la DGT se ha establecido el siguiente cuadro de medidas para cada tipo de ciclo vía de la red actual, con el objetivo de evaluar si cumplen o no con las medidas de seguridad:

Tabla 4: cuadro de anchuras para las distintas ciclovías.

\begin{tabular}{|c|ccc|}
\hline \multirow{2}{*}{ Tipo } & \multicolumn{3}{|c|}{ Anchura } \\
\cline { 2 - 4 } & Mínima & Recomendada & Máxima \\
\hline Pista-bici & Único $=1.5$ & Único $=1.5$ & Único $=1.5$ Doble $=$ \\
& Doble $=2.5$ & Doble $=2.75$ & 2.75 \\
\hline Vía Compartida Interurbana & 2.5 & 2.75 & 5 \\
\hline Ciclo-senda & 2.5 & 2.75 & 5 \\
\hline Carril-bici Protegido & 1.8 & 1.9 & 2.0 \\
\hline Carril-bici (no protegido) & Único $=1.8$ & Único $=1.9$ & Único=2 Doble $=3$ \\
& Doble $=2.5$ & Doble $=2.75$ & \\
\hline Carril de coexistencia & 3.25 & 3.5 & 4 \\
\hline Acera-bici & 2.5 & 2.75 & $\mathrm{X}$ \\
\hline Calles peatonales & $\mathrm{X}$ & $\mathrm{X}$ & \\
\hline
\end{tabular}

Fuente: elaboración propia en base a las normas de la DGT. 
Núñez Lucena, J.J. (2018): "Propuesta de catálogo normalizado de objetos aeronáuticos para el Ecuador", GeoFocus (Artículos), no 22, p. 43-70. ISSN: 1578-5157 http://dx.doi.org/10.21138/GF.605

Una vez establecidas estas medidas de recomendación se ha llevado una medición general de la red actual con un metro en campo. Se da por hecho que estas medidas aportan una noción bastante exacta y generalizada de la situación actual de la red debido a que cada tramo ha sido medido varias veces en distintos puntos. Los resultados obtenidos reflejan una calidad bastante mejorable de la red en cuanto al cumplimiento de las medidas de seguridad que establece la DGT. De los $57.21 \mathrm{~km}$ totales con los que cuenta la red actual tan solo $8.67 \mathrm{~km}$ cumplen las medidas recomendadas y $9.44 \mathrm{~km}$ cuentan con la máxima medida o superior mientras que $4.34 \mathrm{~km}$ se ajustan al mínimo establecido. Los $34.76 \mathrm{~km}$ restantes incumplen la normativa. Esto quiere decir que el $60.76 \%$ de la red supone un riesgo para la seguridad de sus usuarios y que un $68.35 \%$ se sitúa en el mínimo requerido o por debajo. Unas cifras muy elevadas que deberían hacer replantear a la administración local una remodelación de la red por la seguridad de sus ciudadanos. (Figura 5)

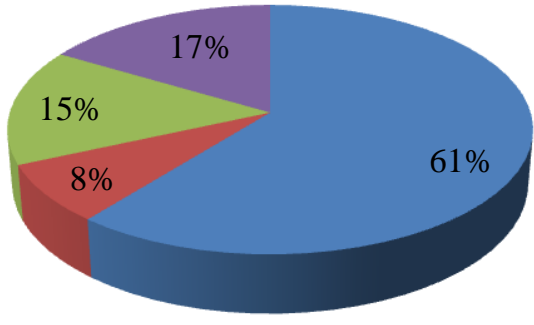

\author{
- Por debajo del mínimo \\ - Valor mínimo \\ Valor medio \\ - Valor máximo o \\ superior
}

\title{
Figura 5: gráfico de sectores de los porcentajes de tramos según su anchura.
}

Fuente: elaboración propia en base a los datos tomados en campo.

En lo que respecta a la interferencia con otros vehículos motorizados o peatones se ha tomado como referencia la clasificación de ciclovías anteriormente expuesta. En este sentido se puede decir que los datos son más positivos puesto que solamente $2,68 \mathrm{~km}$ del total de la red suponen un riesgo elevado para el ciclista (englobando calles peatonales y ciclocalles). En cuanto a aquellas vías totalmente segregadas del tráfico y los peatones, suponen un total de $2.5 \mathrm{~km}$ lo que no parece una cifra muy elevada en referencia al total de la red pero la suma de los carriles bici y las aceras-bici hace un total de $35.26 \mathrm{~km}$. Por lo que la red actual cuenta con un $61 \%$ de vías que se consideran seguras respecto a su segregación del tráfico motorizado. 
Núñez Lucena, J.J. (2018): "Propuesta de catálogo normalizado de objetos aeronáuticos para el Ecuador", GeoFocus (Artículos), no 22, p. 43-70. ISSN: 1578-5157 http://dx.doi.org/10.21138/GF.605

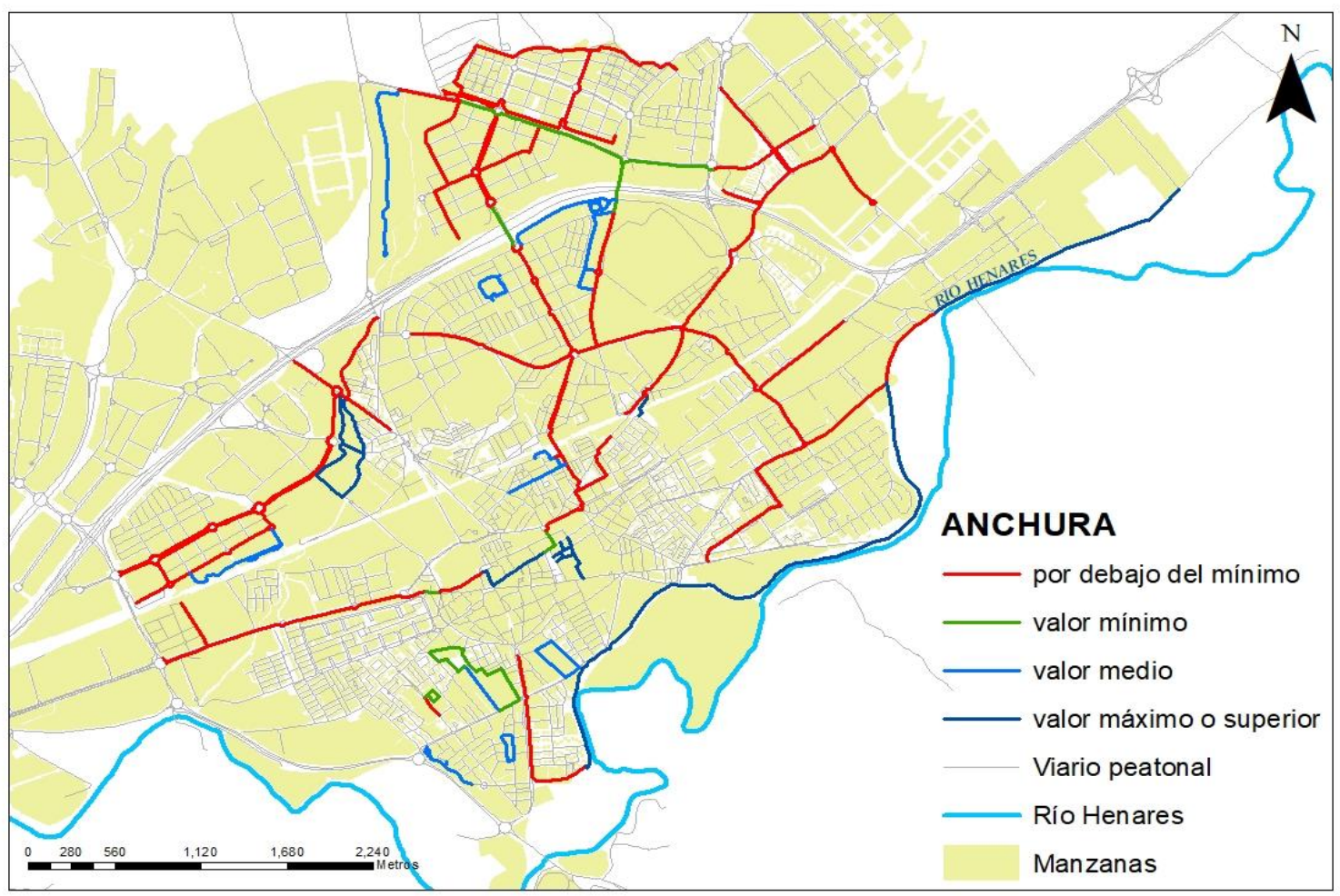

Figura 6: Mapa de la clasificación de ciclovías de la red de carril bici actual de Alcalá de Henares según su anchura.

Fuente: elaboración propia en base a los datos tomados en campo y Cartociudad.

\subsection{Propuesta para la mejora de la red de carril bici de Alcalá de Henares.}

Analizadas las características de la red actual y detectadas sus deficiencias, se cuenta con una base sólida para lanzar propuestas que contribuyan a optimizar su eficiencia. Aunque se han evaluado varios aspectos, este trabajo se centra únicamente en la mejora de la red en lo que se respecta a la estructura del trazado. Siguiendo las recomendaciones de la DGT y la línea de las consideraciones anteriormente expuestas en cuanto a los requisitos que debe cumplir una red. Se han establecido unas pautas muy básicas para llevar a cabo en el diseño de la nueva estructura:

a) Debe cumplir con las características de interconexión y continuidad. Aunque se descarta la totalidad de su conexión debido a los condicionantes del viario, se buscarán alternativas para que la red quede lo más conectada posible a fin de que ésta sea continua y coherente.

b) Deberá garantizar la conexión, lo más directa posible, entre los puntos de origen y los puntos de destino con el objetivo de que sea inmediata. Según la DGT:

"Si un carril bici no se localiza a lo largo de las líneas de deseo, uniendo el mayor número posible de orígenes y destinos por el camino más corto, no será utilizado por muchos ciclistas potenciales." (DGT, 2000, p.1)

c) Deberá integrarse en el viario conectando con otros servicios de transporte público para facilitar y promover la intermodalidad del sistema de transportes en Alcalá de Henares. 
Núñez Lucena, J.J. (2018): "Propuesta de catálogo normalizado de objetos aeronáuticos para el Ecuador", GeoFocus (Artículos), no 22, p. 43-70. ISSN: 1578-5157 http://dx.doi.org/10.21138/GF.605

d) Por último la red deberá conectar todos los barrios de la ciudad para dar cobertura en igualdad a todos los usuarios.

Cumpliendo estas pautas se pretende elevar la potencialidad de la red como medio de transporte alternativo ofreciendo a los usuarios una estructura bien conectada con aquellos puntos de mayor capacidad de atracción e intercambiadores de transporte público, que responda a las necesidades cotidianas y no reducir su uso únicamente para actividades deportivas o para realizar trayectos de corta distancia dentro del casco urbano. (Carril Lugo, 2009, 59)

\subsection{Descripción de la red propuesta.}

La propuesta pretende añadir $23.75 \mathrm{~km}$ a los $57.21 \mathrm{~km}$ ya existentes, conformando una extensión total de $80.96 \mathrm{~km}$. Se ha aprovechado la existencia de la red actual para prolongarla y configurar una nueva estructura dotada de mayor coherencia. Además se ha aumentado el número de aparcamientos de bici para contribuir a fomentar su uso aportando facilidades para los usuarios (León, 2014)

En primer lugar, el nuevo trazado se ha diseñado pensando en su extensión por aquellas calles principales donde tendría sentido que existiese desde un primer momento. Por ello se ha completado la Vía Complutense, la cual estaba provista de algunos tramos pero aislados (uno en el extremo este y otro aproximadamente por el centro de la calle). Posiblemente sea la calle más transitada de Alcalá de Henares en cuanto al tráfico rodado, ya que conecta las zonas Este y Oeste de la ciudad. Por este motivo se ha considerado como una calle prioritaria para el nuevo diseño, extendiéndose por su extremo Este hasta el Centro Comercial La Dehesa y por el extremo oeste hasta el parque O'Donnell.

Además la Vía Complutense supone un enclave estratégico ya que algunas de sus bocacalles se han escogido para unir el Norte y Sur de la ciudad a través de la red propuesta. Por lo tanto, de forma estratégica la propuesta se ha extendido por la calle "Paseo de la Estación" con el objetivo de hacer llegar el carril hasta el apeadero de RENFE y al mismo tiempo unirlo con la ciclocalle que la atraviesa por las calles "Ferraz" y "Cánovas del Castillo". Avanzando hacia Alcalá de Henares Oeste se ha unido Norte y Sur por la "Avenida Daganzo" y la calle "Camarmilla" (también bocacalles de la Vía Complutense), desde esta última extendiéndose hacia el sur por las calles "Andrés Saborit" y "Paseo de las Curas". Abandonando la Vía Complutense el último nexo Norte y Sur que se ha incluido es en el extremo occidental de la ciudad, donde se ha unido la "Avenida del Sol" con "la Garena" a través de la "Avenida Carlos III".

En segundo lugar, destaca la implantación de nuevos carriles en las avenidas de "Juan de Austria" y "Lope de Figueroa". Estas dos avenidas son quizá de las más importantes de la zona sur del municipio, ya que cuentan con un elevado tránsito de peatones y tráfico rodado, por lo que era fundamental que participaran en la nueva articulación de la red. Además cuentan con un gran número de comercios, institutos, colegios y servicios sanitarios, lo cual son motivos de sobra para priorizar su inclusión en la nueva propuesta y dar cobertura a estos servicios.

Por último cabe destacar aquellos pequeños nexos de unión que eran necesarios para otorgar continuidad a la red. Se trata de tramos como el que discurre por las calles "Alfonso VII" y "García Sánchez" que une el barrio de Espartales con el Hospital y el Campus Politécnico. Otro ejemplo sería el de las calles "Colegios" y "Libreros" pensados para articular 
Núñez Lucena, J.J. (2018): "Propuesta de catálogo normalizado de objetos aeronáuticos para el Ecuador", GeoFocus (Artículos), no 22, p. 43-70. ISSN: 1578-5157 http://dx.doi.org/10.21138/GF.605

el centro y conectarse con tramos aislados como el que discurre por la "Plaza de San Diego". De esta forma se trata también de dar importancia al centro de la ciudad y no crear la sensación de una red polarizada en el norte y sur del municipio.

Cabe aclarar que los criterios de diseño empleados se han ceñido a buscar aquellas calles que cuentan con una anchura favorable para la incorporación de una acera-bici. En casos concretos, de no contar con la anchura requerida siempre cabe la posibilidad de hacer una ciclocalle (como por ejemplo en la calle Colegios). Además se ha tratado de que las calles elegidas para el nuevo diseño fueran lo más directas posibles para conectar con otros tramos y que se extendiese hacia calles principales.

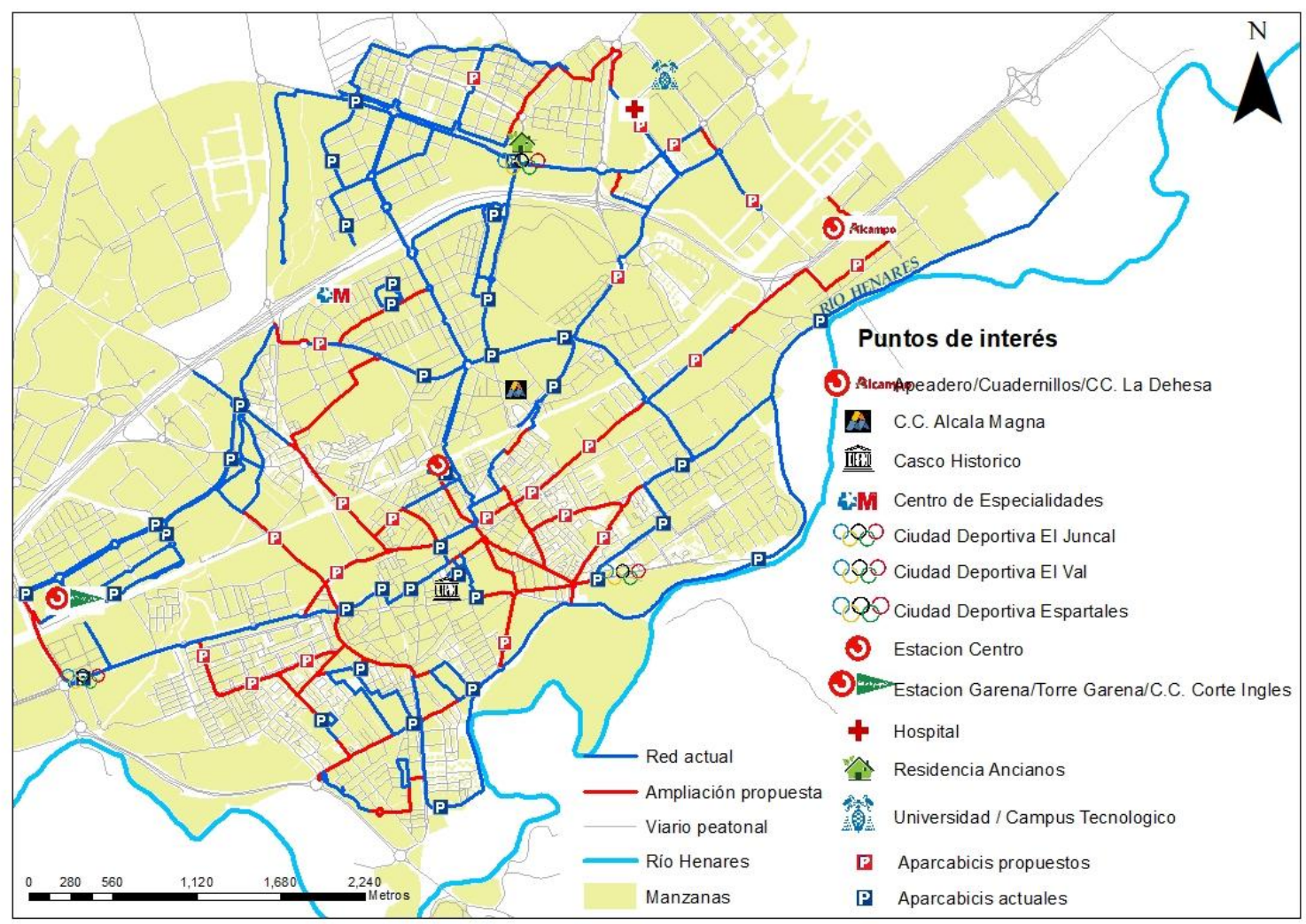

Figura 7: mapa de la red de carril bici propuesta. Fuente: elaboración propia en base a los datos tomados en campo y los datos de Cartociudad.

\subsection{Análisis de eficiencia de la red propuesta.}

Para comprobar con datos cuantitativos la eficiencia de la nueva red propuesta y contar con una información que sostenga la viabilidad de su implementación, se ha procedido a llevar a cabo un análisis de comparación de tiempos empleados por la red actual y la red propuesta. En primer lugar se ha realizado una matriz de orígenes y destinos y en segundo lugar se han establecido una serie de rutas óptimas en cuanto al tiempo empleado. 
Núñez Lucena, J.J. (2018): "Propuesta de catálogo normalizado de objetos aeronáuticos para el Ecuador", GeoFocus (Artículos), no 22, p. 43-70. ISSN: 1578-5157 http://dx.doi.org/10.21138/GF.605

La matriz de origen y destino se ha llevado a cabo a fin de cuantificar el tiempo empleado por un hipotético usuario del carril bici entre cada una de las secciones censales (usando como referencia sus respectivos centroides) y cada uno los principales puntos de interés del municipio. Para determinar los puntos de interés, se han identificado aquellos focos que presentan un mayor grado de atracción para la población del municipio, siendo concretamente los siguientes: Apeadero/Cuadernillos/CC. La Dehesa; Alcalá Magna; Casco Histórico; Centro de Especialidades Francisco Díaz; Ciudad Deportiva "El Juncal"; Ciudad Deportiva "El Val"; Ciudad Deportiva "Espartales"; Estación Centro; Estación Garena/Torre Garena/ C.C. Corte Inglés; Hospital Príncipe de Asturias; Residencia de Ancianos Francisco de Vitoria.

Para la realización de este diagnóstico se han elaborado dos matrices de origen y destino: una para la red actual y otra para la propuesta. Posteriormente se ha elaborado una tercera matriz con la diferencia de tiempos de una red y de otra, cuyos datos han sido los que se han utilizado para sacar las conclusiones en cuestión. A continuación se muestra un cuadro que resume los resultados obtenidos:

Tabla 5: cuadro de resumen de resultados de la Matriz OD.

\begin{tabular}{|lc|cc|}
\hline \multicolumn{4}{|c|}{ DEFINICIÓN DE COLORES Y RESUMEN DE RECUENTO } \\
\hline & & Cuerpo matriz & Totales \\
\hline Pierde & $<\mathbf{0}$ & 0 & 0 \\
\hline Mantiene & $\mathbf{0}$ & 272 & 3 \\
\hline Gana & $>\mathbf{0}$ & 1228 & 122 \\
\hline
\end{tabular}

Fuente: elaboración propia en base a los datos de Cartociudad.

En el cuadro aparecen representados el número total de tramos que la red actual gana, pierde o mantiene estáticos sus tiempos de recorrido respecto a la red actual. De 1500 trazados que la matriz ha elaborado entre cada una de las secciones censales y cada uno de los puntos de interés, 1228 recorridos mejoran mientras que los 272 restantes se mantienen igual. Puede que resulte llamativo que no haya pérdidas de tiempos con la nueva red propuesta. La explicación a esto es que al ser una ampliación de las ciclo vías que conforman la red y por ende aumentar las opciones de itinerarios es imposible que resulten datos negativos.

Para conocer con mayor detalle los resultados se ha procedido a la extracción de algunos estadísticos así como el establecimiento de unos intervalos para segmentar el tiempo. Como ya se sabe, el valor mínimo de la diferencia obtenida en los tiempos de ambas redes es de 0 mientras que el itinerario que experimenta una mayor mejora es de 72.30', algo más de una hora de diferencia. Mientras tanto, de implementar la nueva red propuesta se obtendría un promedio de mejora de 9.59' siendo 1122 recorridos de los 1500 analizados de menos de 15 minutos, es decir, el $74.8 \%$ del total. Por otro lado 343 itinerarios quedarían comprendidos entre los 15 y 30 minutos de mejora mientras que tan sólo 29 casos mejoran entre los 30 y 45 minutos. Finalmente queda mencionar algunos casos de menor importancia como los obtenidos en los tiempos de mejora entre 45 y 60 minutos con 5 resultados y con más de 60 minutos de mejora tan solo consta un caso, el máximo de 72.30' anteriormente mencionado. 
Núñez Lucena, J.J. (2018): "Propuesta de catálogo normalizado de objetos aeronáuticos para el Ecuador", GeoFocus (Artículos), no 22, p. 43-70. ISSN: 1578-5157 http://dx.doi.org/10.21138/GF.605

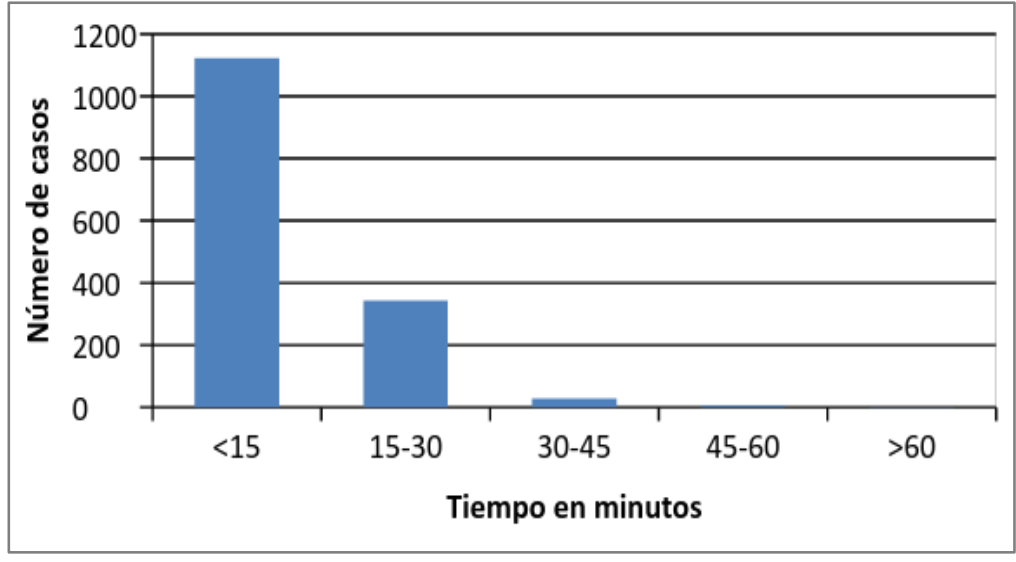

Figura 8: gráfico de barras de la diferencia de tiempos entre la red de carril bici propuesta y la red actual.

Fuente: elaboración propia en base a los datos tomados en campo y los datos de Cartociudad.

Además se han establecido una serie de rutas, entre zonas periféricas y entre éstas y el centro, a fin de comparar los tiempos que se emplean tomando la red actual y los que se emplearían con la nueva red que se propone. A continuación se muestran los datos obtenidos:

Tabla 6: cuadro de comparación de tiempos entre la red de carril bici actual y la propuesta.

\begin{tabular}{|lllcc|}
\hline \multicolumn{2}{|c}{ Rutas periferia-centro } & $\begin{array}{c}\text { Carril bici } \\
\text { actual }\end{array}$ & $\begin{array}{c}\text { Carril bici } \\
\text { propuesto }\end{array}$ & Diferencia \\
\hline \multicolumn{2}{|c}{ Origen Destino } & minutos & minutos & minutos \\
\hline c/Cruz de San Sebastian & Plza. Cervantes & 21.78 & 20.01 & $\mathbf{1 . 7 7}$ \\
\hline c/Miguel Hernández & c/Sebastián de la P.za & 28.95 & 13.47 & $\mathbf{1 5 . 4 8}$ \\
\hline c/Ávila & c/Colegios & 21.71 & 12.78 & $\mathbf{8 . 9 3}$ \\
\hline Av. Reyes Católicos & Plza. Cervantes & 21.57 & 15.71 & $\mathbf{5 . 8 6}$ \\
\hline c/San Ignacio Loyola & c/Sebastián de la P.za & 19.27 & 12.99 & $\mathbf{6 . 2 8}$ \\
\hline c/Fuente del Sol & Plza. Cervantes & 27.06 & 12.3 & $\mathbf{1 4 . 7 6}$ \\
\hline c. Medio Ambiente & Plza. Cervantes & 19.65 & 17.62 & $\mathbf{2 . 0 3}$ \\
\hline \multicolumn{1}{c}{ Periferia-periferia } & & \\
\hline c/Cruz de San Sebastian & c/José Ruíz Azorín & 17.55 & 16.69 & $\mathbf{0 . 8 6}$ \\
\hline c/José Ruíz Azorín & c/Ávila & 24.67 & 23.96 & $\mathbf{0 . 7 1}$ \\
\hline c/Ávila & Av. Reyes Católicos & 27.41 & 15.89 & $\mathbf{1 1 . 5 2}$ \\
\hline Av. Reyes Católicos & c/San Ignacio Loyola & 29.2 & 21.31 & $\mathbf{7 . 8 9}$ \\
\hline c/San Ignacio Loyola & c/Fuente del Sol & 35.67 & 27.69 & $\mathbf{7 . 9 8}$ \\
\hline c/Fuente del Sol & C. Medio Ambiente & 34.05 & 18.75 & $\mathbf{1 5 . 3}$ \\
\hline c. Medio Ambiente & c/ del Juncal & 46.66 & 21.94 & $\mathbf{2 4 . 7 2}$ \\
\hline
\end{tabular}

Fuente: elaboración propia en base a los datos de Cartociudad.

Puede comprobarse que, tanto en los trayectos entre las zonas periféricas y el centro como entre los mismos barrios periféricos, se conseguiría reducir considerablemente los tiempos de implementar la red propuesta. Como ya se ha mencionado anteriormente, esto era de esperar dado que la red propuesta es una ampliación y por lo tanto lo que hace es aumentar las posibilidades de los usuarios. Pero lo llamativo de los resultados obtenidos es la gran diferencia 
Núñez Lucena, J.J. (2018): "Propuesta de catálogo normalizado de objetos aeronáuticos para el Ecuador", GeoFocus (Artículos), no 22, p. 43-70. ISSN: 1578-5157 http://dx.doi.org/10.21138/GF.605

de mejora que se obtendría de implementar la red propuesta. Aunque haya algún caso de mejora de entre 1' y 2' son solo 4 de las 14 rutas establecidas al azar. De las 10 rutas restantes se pueden destacar mejoras de tiempos de entre 6' y hasta cerca de 25 'en la ruta establecida entre las oficinas del Ayuntamiento de la Vía Complutense y la calle del Juncal. Otros tiempos que llaman la atención por su notable mejora son los obtenidos entre la calle Fuente del Sol y la Plaza Cervantes con 14.76' de mejora respecto a la red actual y entre la calle Miguel Hernández y la gasolinera de la Vía Complutense con 15.48'.

Para concluir este punto se ha realizado una tabla de recorridos al azar como los anteriores para comparar los tiempos de la red de carril bici propuesta con los del bus urbano:

Tabla 7: cuadro de comparación de tiempos entre la red de bus urbano y la red propuesta de carril bici.

\begin{tabular}{|llccc|}
\hline \multicolumn{2}{|c}{ Rutas periferia-centro } & $\begin{array}{c}\text { Bus } \\
\text { urbano }\end{array}$ & $\begin{array}{c}\text { Carril bici } \\
\text { propuesto }\end{array}$ & Diferencia \\
\hline \multicolumn{2}{|c}{ Origen Destino } & minutos & minutos & minutos \\
\hline c/Cruz de San Sebastian & Plza. Cervantes & 18.31 & 20.01 & $\mathbf{- 1 . 7}$ \\
\hline c/Miguel Hernández & c/Sebastián de la P.za & 23.16 & 13.47 & $\mathbf{9 . 6 9}$ \\
\hline c/Ávila & c/Colegios & 18.7 & 12.78 & $\mathbf{5 . 9 2}$ \\
\hline Av. Reyes Católicos & Plza. Cervantes & 10.16 & 15.71 & $\mathbf{- 5 . 5 5}$ \\
\hline c/San Ignacio Loyola & c/Sebastián de la P.za & 9.78 & 5.45 & $\mathbf{4 . 3 3}$ \\
\hline c/Fuente del Sol & Plza. Cervantes & 11.54 & 12.3 & $\mathbf{- 0 . 7 6}$ \\
\hline c. Medio Ambiente & Plza. Cervantes & 17.54 & 17.62 & $\mathbf{- 0 . 0 8}$ \\
\hline & \multicolumn{1}{c}{ Periferia-periferia } & & \\
\hline c/Cruz de San Sebastian & c/José Ruíz Azorín & 20.45 & 17.69 & $\mathbf{2 . 7 6}$ \\
\hline c/José Ruíz Azorín & c/Ávila & 33.65 & 24.96 & $\mathbf{8 . 6 9}$ \\
\hline c/Ávila & Av. Reyes Católicos & 21.9 & 15.89 & $\mathbf{6 . 0 1}$ \\
\hline Av. Reyes Católicos & c/San Ignacio Loyola & 14.36 & 21.31 & $\mathbf{- 6 . 9 5}$ \\
\hline c/San Ignacio Loyola & c/Fuente del Sol & 23.29 & 27.69 & $\mathbf{- 4 . 4}$ \\
\hline c/Fuente del Sol & C. Medio Ambiente & 27.62 & 18.75 & $\mathbf{8 . 8 7}$ \\
\hline c. Medio Ambiente & c/ del Juncal & 25.9 & 21.94 & $\mathbf{3 . 9 6}$ \\
\hline
\end{tabular}

Fuente: elaboración propia en base a los datos de Cartociudad.

Se puede observar una considerable mejora de los tiempos respecto a la anterior comparación con la red de carril bici actual. En este caso se obtienen bastantes valores positivos que indican una mejora general de los tiempos obtenidos por la red propuesta respecto a la red de bus urbano, mientras que los tiempos arrojados que indican pérdidas no resultan ser valores muy bajos ya que de las rutas establecidas el resultado más marcado es de una pérdida de casi 7 ' entre la Avenida Reyes Católicos y la calle San Ignacio de Loyola. Otro hecho que puede llamar la atención es que donde se obtienen más resultados positivos es entre las zonas periféricas lo que puede deberse al carácter radiocéntrico de la red de bus urbano. Aun así cabe señalar que las pérdidas de la red de carril bici respecto al bus urbano entre las zonas periféricas y el centro son significativas, siendo el itinerario que más tiempo pierde de poco más de 5' 30' mientras que el resto se mantienen entre 0 y 1 '. 
Núñez Lucena, J.J. (2018): "Propuesta de catálogo normalizado de objetos aeronáuticos para el Ecuador", GeoFocus (Artículos), no 22, p. 43-70. ISSN: 1578-5157 http://dx.doi.org/10.21138/GF.605

\section{Conclusiones y posibles futuras líneas de investigación}

Haciendo balance de todo lo expuesto a lo largo de este trabajo, en el que se ha puesto de relieve las deficiencias estructurales de la red actual de carril bici de Alcalá de Henares y se han mostrado una serie de recomendaciones así como una ampliación de la misma como propuesta de mejora, completando además con un análisis de funcionamiento de ambas redes y comparación de resultados, se ha llegado a una doble conclusión:

Por una parte, la necesidad de cambiar el modelo de desarrollo imperante enfocando la mirada hacia el empleo de energías sostenibles. En este sentido, el carril bici supone una infraestructura que promueve el uso de la bicicleta como un medio de transporte sostenible y respetuoso con el medio ambiente. Cobrando especial importancia el papel que juega en este ámbito los Sistemas de Información Geográfica para la ordenación del territorio en la inclusión y validación de proyectos de este tipo.

Por otra parte, en referencia al caso de estudio, los defectos que la red actual presenta desincentivan su uso. Su estructura inconexa provoca que los usuarios potenciales no la consideren como un medio alternativo de transporte y prefieran seguir utilizando medios convencionales. Asimismo suponen un elevado riesgo para los ciclistas que la utilizan pues incumple las normas de seguridad estipuladas por la DGT de anchos de vía, aun sin contemplarse en el trabajo el estado del pavimento.

No obstante han de considerarse sus potencialidades implícitas como la existencia de un "trazado base" que es adecuado para ser ampliado y mejorado. Los resultados obtenidos de los análisis llevados a cabo reflejan una notable mejora de la eficiencia que tendría la nueva red propuesta en el caso de ser implementada. La comparación de tiempos de los trayectos obtenidos de la propuesta lanzada respecto a la red actual han resultado ser muy favorables e incluso al ser comparados con la red de bus urbano. Lo cual plantea la hipótesis de que, en el caso de materializarse el proyecto, supondría una alternativa viable al transporte convencional en la ciudad de Alcalá de Henares, contribuyendo además a la sostenibilidad del medioambiente evitando la emisión de gases contaminantes a la atmósfera y el agotamiento de los recursos naturales no renovables.

Podría considerarse la propuesta realizada en este trabajo como una invitación a la reflexión sobre el modelo de movilidad deseado en Alcalá de Henares, una invitación que no puede excluir la participación ciudadana. También para este enfoque participativo de la planificación de los Sistemas de Información Geográfica han probado ser herramientas sumamente útiles. Después de haber mostrado en este trabajo la utilidad de la cartografía y del análisis de redes en la evaluación de situaciones y escenarios, poder articular distintas propuestas en un Sistema de Ayuda a la Decisión que facilite la discusión y el consenso entre los agentes locales sería, sin duda, el siguiente paso que habría que abordar. (Férnandez., 2006, 21)

\section{Referencias bibliográficas}

Agencia de Ecología Urbana de Barcelona (2009): Documento para el Plan de Movilidad y

Espacio Público en Lugo. Lugo, Concello de Lugo, [09/08/2016]. Disponible en http://www.bcnecologia.net/es/proyectos/plan-de-movilidad-y-espacio-publico-de-lugo

Ayuntamiento de Zaragoza (2010): Plan Director de la Bicicleta de Zaragoza. Zaragoza, Consejera de Servicios Públicos, [15/07/2016]. Disponible en https://www.zaragoza.es/ciudad/viapublica/movilidad/bici/plan.htm 
Núñez Lucena, J.J. (2018): "Propuesta de catálogo normalizado de objetos aeronáuticos para el Ecuador", GeoFocus (Artículos), no 22, p. 43-70. ISSN: 1578-5157 http://dx.doi.org/10.21138/GF.605

CROW H., Talens (2011): Manual de Diseño para el Tráfico de Bicicletas. Ede (Holanda), CROW FIETSBERAAD, [24/08/2016]. Disponible en http://www.ciclovida.ufpr.br/wpcontent/uploads/2011/07/bpp_pdf/Manual\%20Dise\%C3\%B10\%20Tr\%C3\%A1fico\%20Biciclet as\%20[CROW].pdf

Diputación Foral de Bizkaia (2016): Principales ventajas y obstáculos de la bicicleta como medio de transporte, [15/06/2018]. Disponible en

http://www.bizkaia.eus/fitxategiak/07/Mediateka/1_Principales\%20ventajas\%20y\%20obstaculo s_cas.pdf?hash=1ee223c49b482e262bae82efb8edbc48

Dirección General de Tráfico (2000): Manual de recomendaciones de diseño, construcción, infraestructura, señalización, balizamiento, conservación y mantenimiento del carril bici. Madrid, Ministerio del Interior, [10/08/2016]. Disponible en https://ciudadanabicicleta.files.wordpress.com/2012/01/manual-dgt-2000-disec3b1o.pdf

Domínguez J., Lezama J. (2006): "Medio ambiente y sustentabilidad urbana", Papeles de Población, vol. 12, n 49, pp. 153-176.

Estevan A., Sanz A. (1996): Hacia la reconversión ecológica del transporte en España. Madrid, Los libros de la catarata.

European Commission (1999): Cycling:the way ahead for towns and cities. European Communities, Belgium, [15/06/2018]. Disponible en http://ec.europa.eu/environment/archives/cycling/cycling_en.pdf

Fernández Güell, J. (2006): Planificación estratégica de ciudades. Barcelona, Editorial Reverté, S.A.

Fernández Heredia, Álvaro (2012): El potencial de las variables latentes en modelos explicativos del uso de la bicicleta. Madrid, Universidad Politécnica de Madrid. [15/06/2018]. Disponible en http://oa.upm.es/10716/

Gehl, J. (2006): La humanización del espacio urbano. Barcelona, Editorial Reverté, S.A.

Gobierno de España (2001): LEY 19/2001, de 19 de diciembre, de reforma del texto articulado de la Ley sobre Tráfico, Circulación de Vehículos a Motor y Seguridad Vial, aprobado por Real Decreto legislativo 339/1990, de 2 de marzo. BOE, [22/05/2016]. Disponible en https://www.boe.es/boe/dias/2001/12/20/pdfs/A48427-48437.pdf

Gobierno de España (2009): Real Decreto-ley 13/2009, de 26 de octubre, por el que se crea el Fondo Estatal para el Empleo y la Sostenibilidad Local. BOE. [18/05/2016]. Disponible en https://www.boe.es/diario_boe/txt.php?id=BOE-A-2009-17001

Gutiérrez Moreno, Pablo J. (2014): Análisis y valoración de la experiencia sevillana en movilidad ciclista, recomendaciones para su aplicación en la ciudad de Mérida (México). Sevilla, Universidad de Sevilla.

Higueras, F. (2009): El reto de la ciudad habitable y sostenible. Barcelona, DAPP Publicaciones Jurídicas.

Jiménez, E. (2014): Encuesta de OCU sobre la satisfacción de los ciclistas en las ciudades. Organización de Consumidores y Usuarios. [27/05/2016]. Disponible en https://www.ocu.org/organizacion/prensa/notas-de-prensa/2014/satisfaccion-ciclistas

Junta de Andalucía (2013): Recomendaciones de diseño para las vías ciclistas en Andalucía. Consejería de Fomento y Vivienda, [09/08/2016]. Disponible en 
Núñez Lucena, J.J. (2018): "Propuesta de catálogo normalizado de objetos aeronáuticos para el Ecuador", GeoFocus (Artículos), no 22, p. 43-70. ISSN: 1578-5157 http://dx.doi.org/10.21138/GF.605

http://www.juntadeandalucia.es/fomentoyvivienda/estaticas/sites/consejeria/areas/transportes in fraestructuras/plan_bici/documentos_plan_bici/recomendaciones_diseno_vias_ciclistas.pdf

León P. (2014): Cuánto cuesta un carril bici. El PAÍS, [09/08/2016]. Disponible en http://blogs.elpais.com/love-bicis/2014/02/cuanto-cuesta-un-carril-bici.html\%20

Marqués Sillero, R. (2011): "Sevilla: una experiencia exitosa de promoción de la movilidad en bicicleta en el Sur de Europa", Hábitat y sociedad, n³, pp. 107-130.

Ministerio de Cultura: La evolución urbana de Alcalá de Henares. Ministerio de Cultura, Gobierno de España. [008/08/2016]. Disponible en http://www.ciudadespatrimonio.org/publicaciones/evolucion-urbana/alcala-de-henares.pdf

Osorio Arjona, J. (2015): “Análisis de la red de autobuses de Alcalá de Henares". [Sin publicar].

Pueyo Campos, A. (2001): "El Sistema de Información Geográfica, un instrumento para la planificación y gestión urbana", Geographicalia, n²8, pp. 175-192.

Ruiz-Caro, Ariela (2001): El papel de la OPEP en el comportamiento del mercado petrolero internacional. Santiago de Chile, CEPAL. [08/08/2016]. Disponible en http://www.cepal.org/es/publicaciones/6372-el-papel-de-la-opep-en-el-comportamiento-delmercado-petrolero-internacional

William R., Avedaño C. (2011) "Responsabilidad Social Corporativa (RSC) y Desarrollo Sostenible: una mirada desde la Declaración de Rio de 1992", Respuestas, vol. 16, n², pp. 4559 